AFPEIVED

DEC $2 \& 1995$

$05 T 1$

\section{OAK RIDGE \\ NATIONAL \\ LABORATORY}

LOCKHEED MATTIN /

\section{Different Approaches to Estimating Transition Costs in the Electric-Utility Industry}

Lester W. Baxter
MANAGED BY

LOCKHEED MARTIN ENERGY SYSTEMS, INC. FOR THE UNITED STATES DEPARTMENT OF ENERGY

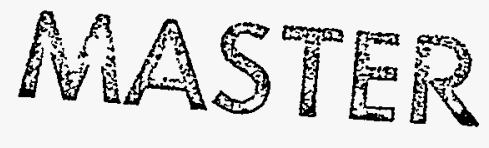

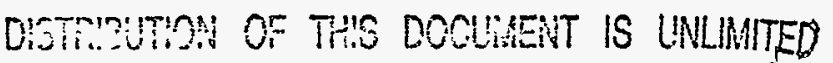


This report has been reproduced directly from the best available copy.

Available to DOE and DOE contractors from the Office of Scientific and Technical Information, P.O. Box 62, Oak Ridge, TN 37831; prices available from (615) 576-8401, FTS 626-8401.

Available to the public from the National Technical Information Service, U.S. Department of Commerce, 5285 Port Royal Rd., Springfield, VA 22161.

This report was prepared as an account of work sponsored by an agency of the United States Government. Neither the United States Government nor any agency thereof, nor any of their employees, makes any warranty, express or implied, or assumes any legal liability or responsibility for the accuracy, completeness, or usefulness of any information, apparatus, product, or process disclosed, or represents that its use would not infringe privately owned rights. Reference herein to any specific commercial product, process, or service by trade name, trademark, manufacturer, or otherwise, does not necessarily constitute or imply its endorsement, recommendation, or favoring by the United States Government or any agency thereof. The views and opinions of authors expressed herein do not necessarily state or reflect those of the United States Government or any agency thereof. 


\title{
DIFFERENT APPROACHES TO ESTIMATING TRANSITION COSTS IN THE ELECTRIC-UTILITY INDUSTRY
}

\author{
LESTER W. BAXTER
}

October 1995

\author{
Sponsored by \\ Competitive Resource Strategies Program \\ Office of Energy Efficiency and Renewable Energy \\ U.S. Department of Energy
}

OAK RIDGE NATIONAL LABORATORY

Oak Ridge, Tennessee 37831 managed by

LOCKHEED MARTIN ENERGY SYSTEMS, INC.

for the

U.S. DEPARTMENT OF ENERGY

under contract No. DE-AC05-84OR21400

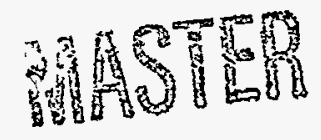

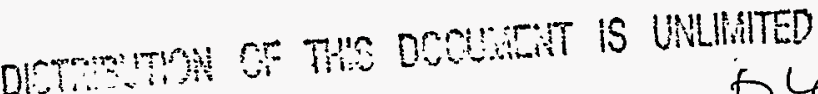





\section{CONTENTS}

Page

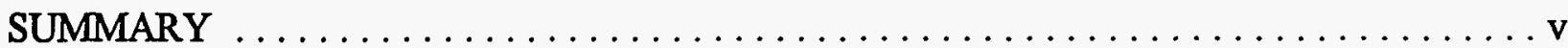

ABBREVIATIONS $\ldots \ldots \ldots \ldots \ldots \ldots \ldots \ldots \ldots \ldots \ldots \ldots \ldots \ldots \ldots \ldots$ vii

CHAPTER 1 INTRODUCTION $\ldots \ldots \ldots \ldots \ldots \ldots \ldots \ldots \ldots \ldots \ldots \ldots \ldots$

DEFINITIONS FOR TRANSITION COSTS $\ldots \ldots \ldots \ldots \ldots \ldots \ldots \ldots \ldots \ldots$

STUDY OBJECTIVES AND METHODS $\ldots \ldots \ldots \ldots \ldots \ldots \ldots \ldots \ldots \ldots$

REPORT OUTLINE ..........................

CHAPTER 2 UNDERSTANDING TRANSITION COSTS $\ldots \ldots \ldots \ldots \ldots \ldots \ldots \ldots$

UTILITY COSTS, RATES, AND TRANSITION COSTS $\ldots \ldots \ldots \ldots \ldots \ldots \ldots$

ECONOMIC APPROACH TO TRANSITION COSTS $\ldots \ldots \ldots \ldots \ldots \ldots \ldots \ldots \ldots$

ASSET VALUATION $\ldots \ldots \ldots \ldots \ldots \ldots \ldots \ldots \ldots \ldots \ldots \ldots \ldots \ldots$

TRANSITION COSTS AND DEREGULATION: SOME IMPLICATIONS

FOR REGULATORS $\ldots \ldots \ldots \ldots \ldots \ldots \ldots \ldots \ldots \ldots \ldots$

CHAPTER 3 ITEMS INCLUDED IN TRANSITION COST ESTIMATES $\ldots \ldots \ldots \ldots$

UTILITY-OWNED GENERATION $\ldots \ldots \ldots \ldots \ldots \ldots \ldots \ldots \ldots \ldots \ldots \ldots \ldots$

LONG-TERM OBLIGATIONS FOR FIRM PURCHASES $\ldots \ldots \ldots \ldots \ldots \ldots \ldots \ldots$

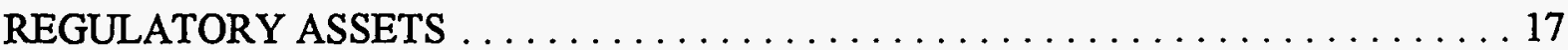

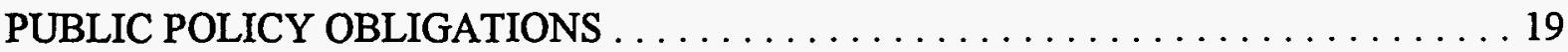

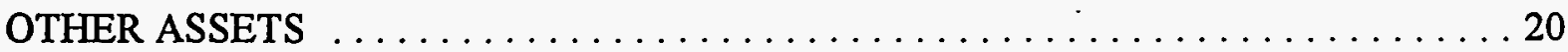

IMPLICATIONS FOR TRANSITION COST ESTIMATION $\ldots \ldots \ldots \ldots \ldots \ldots$

CHAPTER 4 CLASSIFICATION FRAMEWORK FOR DIFFERENT

VALUATION APPROACHES $\ldots \ldots \ldots \ldots \ldots \ldots \ldots \ldots \ldots \ldots \ldots \ldots \ldots \ldots$

CHAPTER 5 ASSESSMENT CRITERIA FOR SPECIFIC APPROACHES $\ldots \ldots \ldots \ldots$

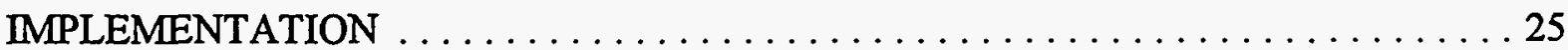

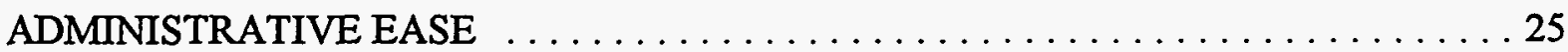

PUBLICLY AVAILABLE DATA OR MODELS $\ldots \ldots \ldots \ldots \ldots \ldots \ldots \ldots \ldots \ldots \ldots$

RELEVANT ASSETS AND LIABILITIES $\ldots \ldots \ldots \ldots \ldots \ldots \ldots \ldots \ldots \ldots$

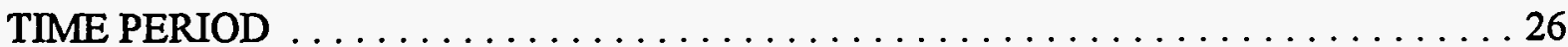

PRICE (VALUE) DETERMINATIONS $\ldots \ldots \ldots \ldots \ldots \ldots \ldots \ldots \ldots \ldots \ldots \ldots \ldots$

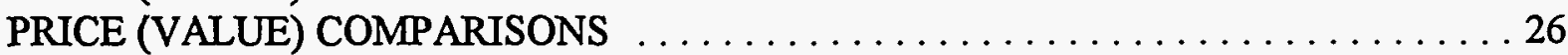

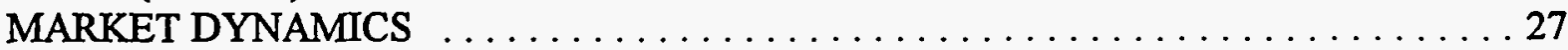


CHAPTER 6 ASSESSING VALUATION METHODS AND APPROACHES $\ldots \ldots \ldots \ldots 29$

VALUATION APPROACHES REVIEWED AND ASSESSED $\ldots \ldots \ldots \ldots \ldots \ldots . \ldots 29$

REVIEW OF SPECIFIC ESTIMATION APPROACHES . . . . . . . . . . . . 30

SUITABILITY OF DIFFERENT METHODS TO SPECIFIC APPLICATIONS . . . . . . 42

CHAPTER 7 CONCLUSIONS AND RECOMMENDATIONS $\ldots \ldots \ldots \ldots \ldots \ldots \ldots 45$

REGULATION AND TRANSITION COSTS ...................... 45

ITEMS INCLUDED IN TRANSITION COSTS $\ldots \ldots \ldots \ldots \ldots \ldots \ldots \ldots \ldots . \ldots 46$

ASSESSING APPROACHES TO ESTIMATING TRANSITION COSTS $\ldots \ldots \ldots \ldots 46$

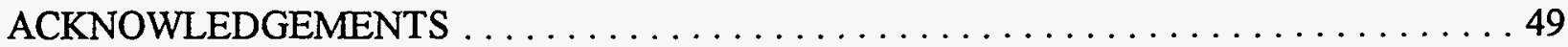

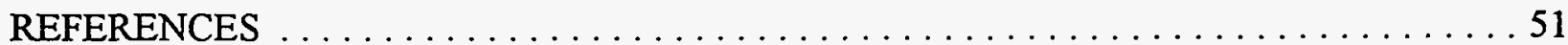

APPENDIX A CATEGORIES USED TO DESCRIBE DIFFERENT

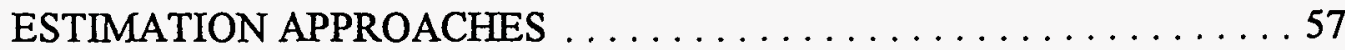

APPENDIX B OVERVIEWS OF SPECIFIC ESTIMATION APPROACHES $\ldots \ldots \ldots \ldots 61$ 


\section{SUMMARY}

The term "transition costs" describes the potential revenue shortfall (or welfare loss) a utility (or other actor) may experience through government-initiated deregulation of electricity generation. The potential for transition costs arises whenever a regulated industry is subject to competitive market forces as a result of explicit government action. Federal and state proposals to deregulate electricity generation sparked a national debate on transition costs in the electric-utility industry. Industry-wide transition cost estimates range from about $\$ 20$ billion to $\$ 500$ billion. Such disparate estimates raise important questions on estimation methods for decision makers.

This report examines different approaches to estimating transition costs. The study hảs three objectives. First, we discuss the concept of transition cost. Second, we identify the major cost categories included in transition cost estimates and summarize the current debate on which specific costs are appropriately included in these estimates. Finally, we identify general and specific estimation approaches and assess their strengths and weaknesses.

We relied primarily on the evidentiary records established at the Federal Energy Regulatory Commission and the California Public Utilities Commission to identify major cost categories and specific estimation approaches. We also contacted regulatory commission staffs in ten states to ascertain estimation activities in each of these states. We refined a classification framework to describe and assess general estimation options. We subsequently developed and applied criteria to describe and assess specific estimation approaches proposed by federal regulators, state regulators, utilities, independent power companies, and consultants.

Regulators and many analysts agree that costs from net generation plant in-service and long-term contractual obligations for power and fuel purchases are appropriately included as transition costs. Agreement is also widespread that the appropriate way to quantify transition costs from generation is by assessing the net change in asset value of a utility's generating portfolio (i.e., the sum of the changes in book-to-market values of a utility's individual generating assets). Substantial disagreement remains about what other generation-related costs, as well as other major cost categories, should be treated as transition costs. We recommend that many publicpolicy obligations currently vested in utilities not be treated as transition costs.

Administrative and market valuation are prominent among general approaches to estimating transition costs. Administrative valuation methods use forecasting, modeling, or other analytical techniques to determine the market and regulated value of utility assets and obligations. Market valuation uses auctions, sales, or asset spin-offs to determine the market value of assets. Every general approach to estimating transition costs has at least one substantive weakness. As a result, regulators must consider combinations of the general approaches or develop solutions to the weaknesses of a selected approach. 
We recommend that regulators consider the following when assessing specific estimation approaches.

- Understand clearly the implementation requirements of each approach, both administrative and technical.

- Assess the relative administrative ease of implementing each approach. For the approaches we reviewed, relative administrative ease decreases as the detail and sophistication of the proposed estimation approach increases.

- Base transition cost estimates used to support utility cost recovery on publicly-available data and models.

- Ensure that the estimation approach includes all relevant assets and liabilities that regulators determine are contributing to transition costs.

- Determine the relevant time period to include in transition cost estimates.

- Carefully assess how the estimation approach estimates market price.

- Ensure that regulated and competitive market prices are constructed comparably. The comparison of regulated market price to competitive market price, which is the characteristic feature of administrative valuation approaches, will provide appropriate results only if the two prices are composed of comparable cost categories. Be aware of the effects of income taxes on transition costs—under administrative valuation approaches, shareholder losses will be net of income taxes.

- Consider the effects of market dynamics over time on transition cost estimates.

We recommend that regulators use administrative valuation approaches to initially assess transition cost problems in their jurisdiction. For regulatory authorization of transition cost recovery, we recommend the use of administrative valuation approaches where continued utility ownership of existing generation and transmission assets is not a major impediment to a competitive power market. At least two options are available to address the forecast risk introduced by administrative approaches. First, regulators can implement a reconciliation process to periodically compare forecasted to observed events and then appropriately adjust subsequent transition cost recovery. Alternatively, regulators can recognize a certain level of forecast error as unavoidable. Reconciliation will then only be initiated if an interested party demonstrates that actual transition costs deviate from the forecast by a predetermined amount.

Market valuation is an attractive approach when continued utility dominance of generation markets impedes the operation of competitive power markets. The sale of less marketable generation assets will be enhanced by combining less attractive with more attractive assets. Disposition of nuclear assets is a key problem with market valuation approaches. Certain of. these assets have productive value, but concerns with future liability for waste storage and plant decommissioning may inhibit market interest. In addition, regulators will still have to use administrative methods to value the contribution of other major asset categories to transition costs. By default, administrative methods must be used to value assets for which no market exists. 


\section{ABBREVIATIONS}

$\operatorname{ATC}_{u}$

CPUC

DSM

EEI

FERC

IREMM

$\mathrm{MCG}_{\mathrm{c}}$

$\mathrm{MCG}_{\mathrm{u}}$

MPUC

NERC

O\&M

PG\&E

PURPA

QF

RDI

ROI

SCE

SDG\&E utility's average total costs

California Public Utilities Commission

demand-side management

Edison Electric Institute

Federal Energy Regulatory Commission

Inter-Regional Electric Market Model

competitor's marginal costs of generation

utility's marginal costs of generation

Maine Public Utilities Commission

North American Electric Reliability Council

operation and maintenance

Pacific Gas \& Electric Company

Public Utilities Regulatory Policies Act

qualifying facility

Resource Data International, Inc.

return on investment

Southern California Edison Company

San Diego Gas \& Electric Company 



\section{INTRODUCTION}

The concern with transition costs is motivated by federal and state proposals to promote increased competition among electricity suppliers. Transition costs are not unique to the electricity industry - transition costs potentially arise whenever a regulated industry is exposed to competition by explicit government action. Recent examples of the effects of government policy on a regulated industry's financial status include deregulation of the telecommunications industry and the natural gas industry (Costello 1994; Graniere 1994). What may be unique about the electricity industry is the size of the potential transition costs involved and the recognition by federal and state regulators that transition cost issues should be addressed while deregulation proposals are being developed and debated and not after selected proposals are implemented.

Our earlier report noted the wide range of transition cost estimates made for the electric-utility industry (Baxter and Hirst 1995). Based on our analysis, the most plausible estimates of transition costs range from $\$ 69$ to $\$ 99$ billion, but we found estimates in the literature that ranged from about $\$ 20$ billion to upwards of $\$ 500$ billion. These disparate estimates, frequently made by parties with a financial stake in the outcome of industry restructuring, underscore at least three central questions on estimation methods for policymakers. First, what estimation methods are available to regulators and legislators to help them determine whether transition costs are a substantial issue for utilities in their jurisdictions? Second, if utilities are to be authorized to at least partially recover transition costs, what approaches are available to regulators for estimating these costs? Third, what are the strengths and weaknesses of the available approaches?

\section{DEFINITIONS FOR TRANSITION COSTS}

The utility industry and industry observers use several different terms to discuss transition costs. The terms "stranded assets," "stranded commitments," "stranded costs," and "stranded investment" are frequently encountered in discussions on the consequences of utility deregulation. Three definitions of "stranded assets" or "stranded costs" are given below. Each emphasizes a distinct and important element of transition costs.

In a competitive market, price is set not by average cost but by the equilibrium in the market. The difference between the competitive market value and the regulated book value is the value of the potential stranded asset (Hogan 1994, p. 2).

Hogan's definition of a stranded asset illustrates the idea that value is defined differently in competitive and regulated markets.

Wholesale stranded costs are defined as any legitimate, prudent and verifiable costs incurred by a public utility or a transmitting 
utility to provide service to a wholesale requirements customer that subsequently becomes, in whole or in part, an unbundled transmission services customer of that public utility or transmitting utility. Retail stranded costs are defined as any legitimate, prudent and verifiable costs incurred by a public utility or transmitting utility to provide service to a retail franchise customer that subsequently becomes, in whole or in part, directly or indirectly, an unbundled transmission services customer of that public utility or transmitting utility (FERC 1994, pp. 2-3).

The Federal Energy Regulatory Commission's (FERC's) definition of stranded costs raises important questions about how a customer's change of status affects the utility that formerly served that customer. Businesses fail and customers routinely migrate out of the utility service area, yet regulators have not considered authorizing the utility to recover the investment made to serve these departing customers. FERC's definition is motivated by the actions government is taking to promote competition in wholesale power generation. These actions will enhance the ability of customers to gain access to the transmission services needed to reach competing wholesale suppliers. Thus, regulatory and legislative concerns with the utility industry's potentially stranded costs arise from government actions to develop competitive generation markets.

Where a customer has a legal obligation to bear certain costs, and finds a way to avoid that obligation, the costs are truly 'stranded.' 'Stranded' costs, therefore, result not merely from costs exceeding market, but from customers leaving without paying costs incurred on their behalf. Put another way, the term 'stranded' should apply only where there is a violation of a quid pro quo. There is a violation of a quid pro quo where (a) the utility was compelled (by contract or franchise) to make an investment and (b) a customer for whom the investment was intended avoids its cost responsibility for that investment (Hempling, Rose, and Burns 1994, p.5).

These authors raise an important distinction. Above-market utility costs only become stranded if no one explicitly pays these costs. Throughout this report, we use the term "transition costs" to describe the potential revenue shortfall (or welfare loss) a utility (or other actor) may experience through government-initiated deregulation of electricity generation. One simple measure of this revenue shortfall is the difference between a utility's embedded cost of generation and a generation price that might result from a competitive generation market. Should ratepayers obtain this competitive price, transition costs will be borne by the utility as a revenue shortfall. Conversely, should the utility continue to recover its full embedded generation costs, ratepayers will experience transition costs as a welfare loss. Our focus is on assessing approaches to estimating these costs, rather than on discussing who should pay these costs and what portion, if any, should remain stranded. In the next chapter, we present an economic definition of transition costs that illustrates how the behavior of different actors-utilities, alternate suppliers, consumers, and regulators-can affect transition costs. 


\section{STUDY OBंJECTIVES AND METHODS}

This study has three objectives. First, we discuss the concept of transition costs. Second, we identify the major cost categories that are included in transition cost estimates. Third, we identify and assess general and specific approaches to estimating the transition costs that individual utilities or regions face.

We relied primarily on the evidentiary records established at FERC (1994; public comments filed at FERC on or about December 9, 1994) and at the California Public Utilities Commission (CPUC 1994a; parties' testimony filed at the CPUC on or about November 18, 1994, and December 5,1994$)$ to identify the major cost categories included in transition cost estimates. Our secondary sources included Anderson, Graham, and Hogan (1993), Flaim (1994), and Rose $(1995 \mathrm{a}, \mathrm{b})$. Our assessment of the relative agreement on which specific cost categories should be included in transition cost estimates is based on the above sources as well as the industry trade press, principally The Electricity Journal and Public Utilities Fortnightly.

To identify specific estimation approaches, we again relied on the evidentiary record established at FERC and the CPUC. The CPUC's record was particularly instructive because the California investor-owned utilities filed preliminary transition cost estimates accompanied by supporting documentation. We also used the results of our initial study to identify states where transition costs may be a concern for regulators (Baxter and Hirst 1995). We focused on ten states where our analysis suggested the absolute magnitude of transition costs may be high (California, Florida, Illinois, Massachusetts, Minnesota, New Jersey, New York, Ohio, Pennsylvania, Texas) and contacted regulatory commission staffs to determine the nature of estimation activities in each of these states. As of October 1995, only California has conducted hearings on transition cost estimates; these hearings are part of that state's utility restructuring proceeding.

In assessing different estimation approaches, we refined a general classification framework first presented by San Diego Gas \& Electric Company (SDG\&E 1994a). We subsequently developed and applied criteria to describe and assess specific estimation approaches (see Appendix A and Chapter 5). Our main focus as we reviewed both general and specific approaches was on their application by regulators to estimate those transition costs that utilities will at least partially recover.

\section{REPORT OUTLINE}

Chapter 2 more fully discusses the concept of transition costs and examines some implications for regulators. Chapter 3 presents items included in transition cost estimates and summarizes arguments from the continuing national debate about what items appropriately belong in these estimates. Chapter 4 describes a classification framework for different general valuation approaches. Chapter 5 presents eight criteria used to assess different valuation approaches and Chapter 6 assesses several specific approaches using these criteria. Chapter 7 presents conclusions and recommendations from the study. 


\section{UNDERSTANDING TRANSITION COSTS}

This chapter first discusses the relationship between utility costs, rates, and transition costs. We then present an economic approach to understanding transition costs and discuss different principles of asset valuation. We focus the conceptual discussion by identifying the implications of regulators taking action on transition costs, depending on the speed of deregulation.

\section{UTILITY COSTS, RATES, AND TRANSITION COSTS}

That the focus of deregulation proposals is on generation has important consequences for utilities. In 1993, investor-owned electric utilities spent $67 \%$ of total revenue on generation, $15 \%$ on distribution, $9 \%$ on administrative and general costs, $6 \%$ on transmission, and $4 \%$ on customer service. As Figure 1 illustrates, generation costs dominate total utility costs. In addition, fixed costs represented approximately $63 \%$ of total utility costs in 1993. Further, fixed generation costs accounted. for about $47 \%$ of total utility generation costs. ${ }^{1}$

Regulators set prices for utility service that enable the utility to collect the total amount of money from customers the utility needs to pay all operating and capital costs plus a fair return on investment (Bonbright, Danielsen, and Kamerschen 1988). Utility and regulatory accounting practice includes a portion of fixed and variable cost recovery for each $\mathrm{kWh}$ the utility sells. Even customers with demand charges pay some portion of fixed costs through the energy rate. Thus, even though by definition fixed costs are essentially constant and do not change over the short term with the utility's level of production, each $\mathrm{kWh}$ sold contributes to fixed cost recovery.

Under traditional regulation and rate making, customer rates are bundled; that is, all costs of utility service are included in a single rate schedule. The resulting temptation is great for customers to compare a utility's bundled prices, which reflect generation, transmission, distribution, and related ancillary services, to the generation-only prices of alternate suppliers. Once competition is introduced, a utility's revenue loss, which represents unrecovered fixed costs to the utility, may stem from losing customers to alternate generation suppliers or the utility's need to reduce retail or wholesale rates to maintain market share. Under most circumstances, both events will result in lost revenue to the utility, though the specific financial consequences depend on whether the utility is able to retain its customers. Should the utility be

\footnotetext{
'Estimating fixed costs is difficult because the calculation depends heavily on the time period evaluated. In the above estimates, we assigned $75 \%$ of the nonenergy operation and maintenance (O\&M) costs associated with generation to fixed costs. For transmission and distribution we assigned $75 \%$ of $O \& M$ costs to fixed costs. We assigned $100 \%$ of customer service and administration and general costs to fixed costs.
} 
unable to collect revenue sufficient to cover its fixed costs of service, a certain portion of its asset base becomes "stranded" and the utility will take a potentially substantial charge against earnings (Baxter and Hirst 1995). Below, we examine the implications of traditional rate making and the actions of regulators, utilities, suppliers, and consumers on transition costs.

\section{ECONOMIC APPROACH TO TRANSITION COSTS}

Rose (1995a) provides a useful economic approach to transition costs, which is illustrated for a hypothetical utility in Figure 2. The top curve represents the utility's average total cost (ATC $)$ for all services, which approximates its rate at different levels of output. Figure 2 depicts the right portion of the average total cost curve, after the utility's economies of scale are exhausted. The next curve represents the utility's marginal cost of generation $\left(\mathrm{MCG}_{\mathrm{u}}\right)^{2}$ Again, Figure 2 shows only the right portion of the curve. The key assumption is that the utility's marginal cost of generation exceeds its average cost of generation (the latter is not shown on the graph). This assumption leads to average total cost and marginal cost curves with positive slopes over the range of output considered. We note that these two curves are intended to characterize a utility with positive net transition costs; many utilities may have marginal generation costs below average generation costs, with different implications for transition costs. A competitor's marginal cost of generation $\left(\mathrm{MCG}_{\mathrm{c}}\right)$ is shown by the final curve. This curve assumes higher marginal costs at low production levels, declining unit costs as production increases, and increasing unit costs at high production levels. This curve can also represent the market price of electricity from multiple suppliers. Finally, the quantities $Q_{1}, Q_{2}$, and $Q_{3}$ represent small incremental increases in supply.

Figure 2 illustrates three examples. At quantity $\mathrm{Q}_{1}, \mathrm{MCG}_{\mathrm{c}}>\mathrm{ATC}_{\mathrm{u}}$, and transition costs are zero because customers will not leave the utility system. At $\mathrm{Q}_{2}, \mathrm{ATC}_{\mathrm{u}}>\mathrm{MCG}_{\mathrm{c}}$, and the utility may incur transition costs or lost revenue $\left(\mathrm{ATC}_{\mathrm{u}}-\mathrm{MCG}_{\mathrm{u}}\right)$ because customers will leave the utility system if faced with these price signals $\left(\mathrm{ATC}_{\mathrm{u}}\right.$ versus $\mathrm{MCG}_{\mathrm{c}}$ ). In this case, the customer's decision to leave the utility system is an inefficient allocation of society's resources because $\mathrm{MCG}_{\mathrm{c}}>\mathrm{MCG}_{\mathrm{u}}$. Two actions are possible to avoid this inefficient allocation. First, the utility may offer a rate discount (at least $A T C_{u}-M_{c}$ ), thereby retaining the customer but suffering a revenue loss equal to this discount. The utility may have to reduce earnings or increase rates to other customers to recover this lost revenue. Second, the regulator may unbundle rates into at least two components. The first part would be a generation price set at $\mathrm{MCG}_{\mathrm{u}}$; the second part would be a system price set at $\mathrm{ATC}_{\mathrm{u}}-\mathrm{MCG}_{\mathrm{u}}$. All electricity users connected to the utility's

\footnotetext{
${ }^{2}$ This example considers competition to provide an incremental increase in supply. Thus, the utility and alternate suppliers are competing to provide this additional level of supply with their existing plants. As a result, the marginal generation costs in our example are short-run (i.e., variable) costs. As a practical matter, marginal costs are difficult to measure and depend critically on the precise time period under consideration (Kahn 1970). Generation costs for a single utility can differ substantially over a day. When attempting to attain optimal pricing, economists disagree about whether prices should be set using short-run marginal costs (Kahn 1970; Andersson and Bohman 1985) or long-run marginal costs (Shepherd 1985). Kahn (1970) argues that the short-run measure is theoretically preferred, but that the long-run measure is more practical to implement.
} 


\section{Generation}

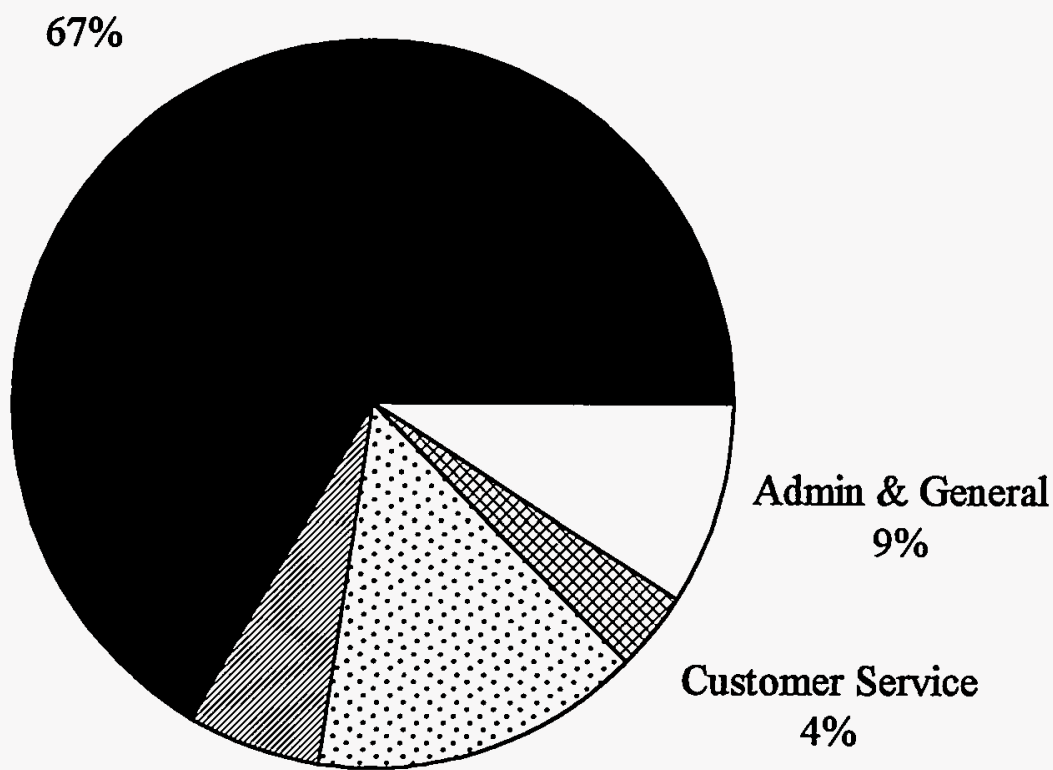

Transmission Distribution $6 \%$ $15 \%$

Figure 1. Distribution of costs by major function for U.S. investor-owned electric utilities in 1993 (Source: Energy Information Administration 1995).

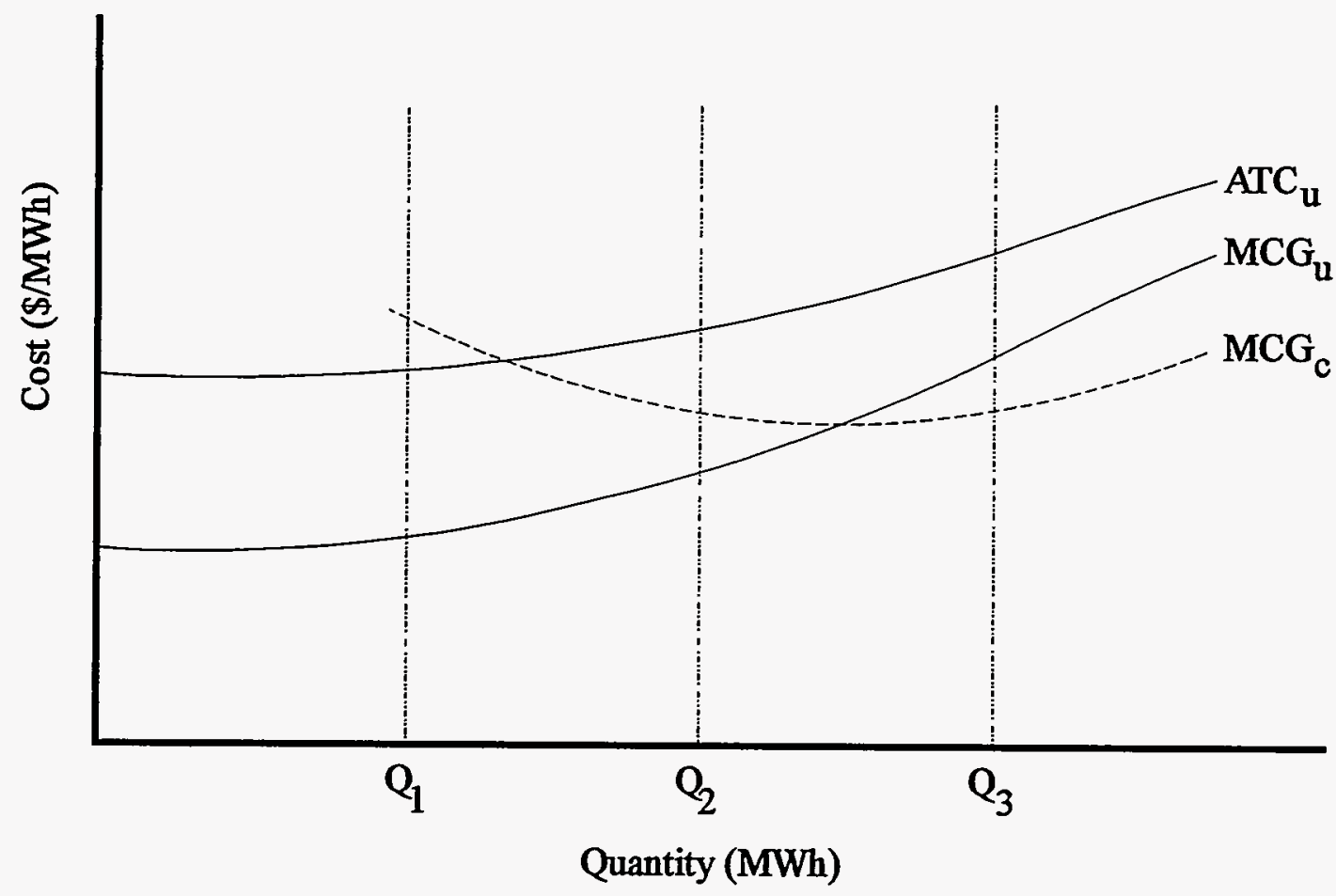

Figure 2. The relationship of a utility's total costs and marginal costs of generation to a competitor's marginal costs of generation (Source: Adapted from Rose 1995a). 
distribution system would pay this system price. Under this second action, the customer would make the efficient choice, continue to purchase electricity generated by the utility, and transition costs would be zero. At $\mathrm{Q}_{3}, \mathrm{MCG}_{\mathrm{u}}>\mathrm{MCG}_{\mathrm{c}}$, and the efficient choice for the customer and society is for the customer to leave the utility generation system and purchase electricity generated by the utility's competitor. Without any action by the utility or regulators, the transition costs equal $\mathrm{ATC}_{u}-\mathrm{MCG}_{\mathrm{u}}$. Alternatively, the utility may offer a rate discount of $\mathrm{ATC}_{u}$ - $\mathrm{MCG}_{\mathrm{c}}$ to retain the customer, but incurs a revenue loss that equals this discount. This may also be considered a transition cost, but because the utility is inducing the customer to make an inefficient choice, regulators should be disinclined to permit the utility to recover this lost revenue from other customers. As in the second case, regulators may unbundle rates. If the customer leaves the utility system, the utility would continue to collect the system fee of $\mathrm{ATC}_{u}$ $\mathrm{MCG}_{\mathrm{u}}$ and the customer would reap the benefit of the difference between the utility's and the competitor's marginal costs of generation. The transition costs in this case are any unrecovered fixed generation costs associated with the bypassed utility generation.

The important lesson from this example is that utilities and regulators can influence transition costs. Utilities can mitigate transition costs by reducing their total costs and pursuing markets where they can offer competitive service. The example further illustrates that the effect of competition on the utility's finances depends on whether the utility keeps or loses customers. Regulators can provide accurate and comparable price signals to consumers by unbundling rates or designing appropriate exit fees that discourage uneconomic bypass of utility generation. The example also makes clear that transition costs cannot be estimated in advance without making assumptions about the timing and nature of restructuring. These restructuring decisions, whether made piecemeal or in a comprehensive fashion, will determine when customers get access to alternative suppliers and what policies regulators develop to encourage productive efficiency. Restructuring will also affect the utility's cost structure and the market price for power.

\section{ASSET VALUATION}

Assets are valued differently in regulated and competitive environments. In a pure regulated environment, an asset's market value will equal its book value. To see that this is so we need only consider how prices are established in a regulated environment. Regulated prices are set to recover costs, pay debt, and provide a reasonable return to shareholders. In principle, the future revenues from an asset should equal the investment made in the asset plus the shareholder's return on investment (ROI). Regulators in most jurisdictions use original cost methods to determine the value of a utility's assets (Bonbright, Danielsen, and Kamerschen 1988). Public utilities may recover only the asset's original cost through rates. Book value is simply an asset's original cost minus accumulated depreciation. Thus, asset value is related to sunk cost; this result is unique to regulated environments.

In a competitive environment, the value of an asset equals the expected present value of the profits an asset can generate under its best use, which equals the excess of expected revenues over expected costs (Copeland and Murrin 1990). Asset value is thus directly related to the 
market price that can be obtained for the goods or services that the asset produces. Value is not fixed but changes over time in response to market conditions. In competitive markets, the price of services that flow from an asset is determined by the market equilibrium, which results from numerous exchanges between willing buyers and willing sellers. Economic theory tells us that in perfectly competitive markets, efficient resource allocation criteria are met when the price of a good or service equals its marginal production cost. Yet these marginal-cost-based prices may have no relationship to the historical average costs of individual firms. At a given equilibrium price, some firms may enjoy temporary profits, where price exceeds their average costs, while other firms may face temporary losses. In a competitive environment, asset value is unrelated to sunk costs.

\section{TRANSITION COSTS AND DEREGULATION: SOME IMPLICATIONS FOR REGULATORS}

The possible consequences of taking action on transition costs depend on the effects of specific deregulation proposals. A key feature of these proposals that directly affects transition costs is how fast the move to deregulate electricity generation takes place. The more quickly regulators move to deregulate generation (and hasten the anticipated efficiency benefits that competition will bring), the greater the transition costs borne by utilities. A slower move to deregulate generation will impose greater transition costs on consumers.

Table 1 describes some possible consequences of taking regulatory action on transition costs when deregulation occurs quickly (three years or less) or slowly (five years or more). By "taking action" on transition costs, we mean that regulators authorize utilities to at least partially recover transition costs. Two points from this table deserve emphasis. First, if regulators move quickly to deregulate electricity generation and take no action on transition costs, electricity prices for certain customers will drop quickly and substantially. Another probable consequence is that certain utilities will suffer substantial financial losses. The possibility of utility bankruptcies is higher in this case than the others presented in the table. Second, the remaining three cases have broadly similar consequences. Important differences do exist between the remaining three cases, but they also share two important consequences:

- substantial and immediate decreases in electricity prices are unlikely (i.e., welfare losses to consumers are increased) and

- financial damage to utility shareholders is reduced.

Regulators that act to ensure that at least some portion of utility transition costs do not become stranded will find it difficult to achieve large rate reductions for broad groups of customers. Costs that would otherwise be stranded continue to be collected from electricity users. Once these costs are recovered, generation prices will almost certainly decline.

Deregulation of electricity generation will cause the asset valuation principles we discussed to be applied. In Case 1, the market itself will operate to apply these principles. Utilities with assets 
Table 1. Possible consequences of regulatory action on transition costs

\begin{tabular}{|c|c|c|c|}
\hline & \multicolumn{2}{|l|}{ Move to deregulate generation } \\
\hline & & Faster & Slower \\
\hline \multirow[t]{2}{*}{$\begin{array}{l}\text { Public } \\
\text { utilities } \\
\text { commis- } \\
\text { sion } \\
\text { action on } \\
\text { transition } \\
\text { costs }\end{array}$} & $\begin{array}{l}\text { No } \\
\text { action }\end{array}$ & $\begin{array}{l}\text { Case } 1 \\
\text { - prices fall quickly (at least for } \\
\text { customers with choice) } \\
\text { - utilities with high generation } \\
\text { costs write down uneconomic } \\
\text { assets } \\
\text { - uneconomic assets retired or } \\
\text { mothballed } \\
\text { - affected utilities see large } \\
\text { reductions in stock prices } \\
\text { bankruptcies at some affected } \\
\text { utilities }\end{array}$ & $\begin{array}{l}\text { Case } 2 \\
\text { prices fall slowly or not at all } \\
\text { (where regulated prices are not } \\
\text { based on marginal costs, } \\
\text { individual rate classes may see } \\
\text { larger shifts) } \\
\text { - utilities recover at least a } \\
\text { portion of transition costs } \\
\text { through rates } \\
\text { - utilities move to cut costs to } \\
\text { prepare for competition (cost } \\
\text { reductions are offset by } \\
\text { accelerated recovery of costs at } \\
\text { risk) } \\
\text { uneconomic assets retired or } \\
\text { mothballed } \\
\text { number of bankruptcies reduced }\end{array}$ \\
\hline & $\begin{array}{l}\text { Some } \\
\text { action }\end{array}$ & $\begin{array}{l}\text { Case } 3 \\
\text { Same as Case } 2 \text { except: } \\
\text { prices decline if alternate } \\
\text { suppliers have lower marginal } \\
\text { generation costs or if utilities } \\
\text { can reduce costs } \\
\text { certain utilities see some } \\
\text { reductions in stock prices }\end{array}$ & $\begin{array}{l}\text { Case } 4 \\
\text { Same as Case } 2 \text { except: } \\
\text { - prices decline if alternate } \\
\text { suppliers have lower marginal } \\
\text { generation costs or if utilities } \\
\text { can reduce costs } \\
\text { pressure for utilities to cut costs } \\
\text { is not as great } \\
\text { - uneconomic assets are retired or } \\
\text { mothballed (but probably } \\
\text { operate through transition } \\
\text { period) }\end{array}$ \\
\hline
\end{tabular}

that cannot recover fixed generation costs at market prices for electricity will be forced to write 2 , utilities may eventually be faced with a similar prospect, but the benefit of time provides an opportunity to cut costs and recover at least some of the book value for assets that can recoup 
fixed costs at prevailing market prices. ${ }^{3}$ In Cases 3 and 4, asset valuation principles can be applied directly through analytical exercises or through a sale. The analytical approach assesses expected profits or losses by forecasting or observing market conditions. In the sale of assets, the bids themselves represent different buyers' expectations of the present value of future profits.

${ }^{3}$ We note that higher inflation rates over time will reduce the transition costs borne by utilities. A sizeable fraction of generation costs are fixed nominally (approximately $35 \%$ in 1993). Higher inflation will raise wholesale prices (and revenues) without commensurate increases in these fixed costs. 



\section{ITEMS INCLUDED IN TRANSITION COST ESTIMATES}

The national debate on transition costs has produced a wide range of positions concerning which assets and liabilities should be included in these estimates. For those who argue that regulators should ignore transition costs, the issue is moot. On this side of the debate, transition costs do not exist (or their importance is greatly exaggerated), should have been anticipated by utilities, or are the result of poor management decisions (Michaels 1994; American Public Power Association 1994; ELCON, AISI, and CMA 1994). Others argue that a utility's full future revenue requirement, as established under the expectation of a continuation of historical regulation, should define the assets and liabilities to include in transition cost estimates (EEI 1994; Utility Working Group 1994). From this side of the debate, utilities are participants in a regulatory compact that obligated them to serve all customers and, in the last two decades, subjected internal management decisions to regulatory and legislative constraints.

This chapter focuses on the items that could be included in transition cost estimates. In Table 2 we list four major categories of costs: utility-owned generation, long-term obligations for firm purchases, regulatory assets, and public policy programs. Each of these major categories has entered prominently in the debate on transition costs. We also list more specific cost categories and indicate where there seems to be either relative agreement or disagreement on which costs to include. Because of the wide range of positions on the subject, others might make this distinction differently. In addition, while analysts may agree that certain costs should be included in transition cost estimates, policymakers may decide to allow only partial recovery of certain of these costs. For example, analysts agree that net plant in service should be included in transition cost estimates, but policymakers may decide not to allow cost recovery for that portion of net plant that represents excess capacity.

An important observation from Table 2 is that there appears to be widespread agreement that certain costs arising from utility-owned generation and all costs from long-term contractual obligations should be included as transition costs. The national debate has not produced any agreement on the treatment of other major cost categories. We discuss each of the major cost categories below and discuss why there is agreement on certain costs and why disagreement continues for a wide range of costs.

\section{UTILITY-OWNED GENERATION}

Except for utilities that purchase substantial energy, generation costs result from the utilities' own plants. Proposals to restructure the electric utility industry broadly agree that the generation function should no longer be subject to price regulation and should thus be made fully competitive over time. Most restructuring proposals also agree that the transmission and 
Table 2. Items included in transition cost estimates

\begin{tabular}{|c|c|c|}
\hline \multirow[t]{2}{*}{ Major categories } & \multicolumn{2}{|c|}{ Specific costs } \\
\hline & Agreement & Disagreement \\
\hline $\begin{array}{l}\text { Utility-owned } \\
\text { generation }\end{array}$ & $\begin{array}{l}\text { net transition costs from net plant in } \\
\text { service } \\
\text { - other fixed costs }\end{array}$ & $\begin{array}{l}\text { gross transition costs from net plant in } \\
\text { service } \\
\text { - } \text { return on investment } \\
\text { - common plant associated with } \\
\text { generation service } \\
\text { - construction work in progress } \\
\text { - plant held for future use } \\
\text { - plant additions } \\
\text { - future variable costs }\end{array}$ \\
\hline $\begin{array}{l}\text { Long-term obligations } \\
\text { - Power-purchase } \\
\text { contracts } \\
\text { - Fuel-supply } \\
\text { contracts }\end{array}$ & $\begin{array}{l}\text { - energy payments } \\
\text { capacity payments } \\
\text { other payments tied to deliveries } \\
\text { payments for deliveries as specified in } \\
\text { contracts }\end{array}$ & - \\
\hline Regulatory assets ${ }^{1}$ & - & $\begin{array}{l}\text { - deferred taxes }(\$ 42) \\
\text { phase-in, synchronization, and other } \\
(\$ 18) \\
\text { - unrecovered plant costs }(\$ 6) \\
\text { - unamortized loss on reacquired debt } \\
\text { (\$5) } \\
\text { - pensions, other post-employee } \\
\text { benefits, and early retirements }(\$ 3) \\
\text { - decommissioning costs }(\$ 2) \\
\text { - fuel costs }(\$ 2) \\
\text { - capitalized demand-side management } \\
\text { costs }(\$ 1)\end{array}$ \\
\hline Public policy programs ${ }^{2}$ & & $\begin{array}{l}\text { - energy efficiency } \\
\text { - low-income weatherization } \\
\text { - research and development } \\
\text { - fuel diversity } \\
\text { - renewable energy } \\
\text { - economic efficiency } \\
\text { - environmental protection }\end{array}$ \\
\hline
\end{tabular}

1. See Edison Electric Institute (EEI 1994) for its more complete list of regulatory assets. The number in parentheses are EEI's estimates of the balance of these assets (in billions of \$) at the end of 1993.

2. See Tonn, Hirst, and Bauer (1995) for a more complete list of public policy programs. 
distribution functions remain a natural monopoly that require some form of continued price regulation. As a result of this focus on generation deregulation, many analysts now agree that certain costs associated with utility-owned generation are properly included in transition cost estimates.

Table 2 lists several specific costs linked to utility-owned generation. Net plant in service is the original plant cost minus accumulated depreciation. Consensus is growing that the appropriate way to include net plant in service is by considering the net change in asset value of a utility's entire generating portfolio. With the advent of competition, the book-to-market value of the utility's generating assets will change. Some assets will have a market value below their book value while other assets will have a market value that exceeds book. The sum of these changes (some positive, some negative) is the net change in asset value of the portfolio. A utility with a negative net asset value would not be able to produce revenue sufficient to recover net plant in service. The other fixed costs associated with generation, primarily taxes, interest payments, and O\&M expenses, may also be included to the extent that they contribute to a utility's abovemarket generation costs.

An important exception exists to the agreement on including net plant in service. The debate continues on how to treat net plant from uneconomic units - plants with variable costs that will probably exceed the market price for electricity in the foreseeable future. The debate centers on whether transition costs should include any portion of net plant or the rate of return for this portion of the rate base. Proponents of including these items argue that utility shareholders should be allowed to recover these investments, particularly if the facilities will be closed. Opponents argue that these facilities are bad investments that do not justify full cost recovery. One overlooked aspect to this debate is the contribution these plants make to generation- and transmission-related ancillary services, such as spinning reserve, stability enhancement, and voltage support. The costs of many of these services are low while the economic consequences of not providing certain ancillary services can be quite high (Kirby, Hirst, and Vancoevering 1995). Unbundling and charging for ancillary services is another way for utilities to mitigate transition costs. ${ }^{4}$

There is considerable disagreement about what other generation costs should be included as transition costs. Proposals to include only net plant with market value below book value as a transition cost (representing gross transition costs) still surface but are no longer seriously considered. Disagreement also continues about whether ROI is a transition cost. Some analysts argue that the full ROI be considered a transition cost. Others argue that investors should be allowed to recover their capital investment, but not be guaranteed recovery of anticipated earnings or interest payments. Still others argue that investors should expect recovery of their capital and anticipated interest, but not anticipated profits from generation facilities.

4As a simple example, a utility with embedded generation costs of $5 \notin / \mathrm{kWh}$, and faced with wholesale market prices of $2 \phi / \mathrm{kWh}$, can reduce its transition costs to $3 \phi / \mathrm{kWh}$ minus any revenue obtained from selling its ancillary services. 
Among the remaining cost items, more observers will agree that past costs are more appropriately included as transition costs than future costs. Common plant (e.g., buildings and equipment, used to provide more than one utility service), construction work in progress (an account that records all capital costs of constructing new utility facilities) associated with generation service, and plant held for future use (land or land rights purchased for future construction of utility facilities) are past costs.

Plant additions (the amount added to plant in service during a specified period) in the form of incremental capacity, environmental controls, or additional safety features and variable costs are future costs. A utility's future decision to add additional capacity, unless directed by regulators, should be considered a shareholder risk. It is less clear that the addition of pollution control equipment to meet local, state, or national pollution standards should be omitted unless all generators are subject to the same standards. Similarly, all generators face future variable costs, such as fuel and certain O\&M expenses. Including variable costs as transition costs, and thereby providing the utility assurance that it will recover its above-market variable costs, will reduce a utility's incentive to lower these costs.

\section{LONG-TERM OBLIGATIONS FOR FIRM PURCHASES}

Electric utilities enter into two types of long-term (beyond five years) supply obligations: powerpurchase contracts and fuel-supply contracts. Power-purchase contracts can be between two utilities, or a utility and a qualifying facility $(\mathrm{QF})$ or independent power producer, for delivery of firm energy or capacity, or both.

Because these contracts deal directly with generation services, agreement is generally widespread that certain specified contract costs are properly included in transition cost estimates. Contracts between utilities are subject to FERC approval. QFs are a class of nonutility generators created by the Public Utilities Regulatory Policies Act (PURPA) of 1978 that must meet operating, efficiency, and fuel-use standards established by FERC, which implements PURPA. FERC delegated some PURPA implementation authority to states, including state approval of the capacity and energy prices utilities pay to QFs. Contracts with QFs typically run from 10 to 30 years and may have only limited dispatchability provisions. Independent power producers are nonutility power generators that sell power at wholesale rates to utilities under terms approved by FERC. The wholesale rates include payments for firm capacity or energy, or both.

QFs, as offspring of PURPA, are a creation of government policy. As a result, agreement is stronger that shareholders should not be at risk for any above-market costs from these contracts. Because many of these contracts extend well into the next century, utilities are actively renegotiating agreements or buying out the contracts. To the extent that utilities voluntarily entered into power-purchase contracts with other utilities or independent power producers, observers are less likely to agree that above-market costs should be treated as transition costs. Alternatively, utilities that entered into these power-purchase contracts as a result of 
government-supported resource planning rules or policies can argue more persuasively to include any above-market costs as transition costs.

Long-term fuel supply contracts are agreements with fuel suppliers to provide fossil fuel for electricity generation. ${ }^{5}$ The relevant payments are specified in contracts and tied to specific fuel deliveries for five- to fifteen-year periods. ${ }^{6}$ As with power-purchase contracts, the strength of agreement on whether above-market costs from these contracts should be included as transition costs depends on whether utilities entered contracts voluntarily and of their own initiative or as an outcome of government-supported resource planning rules or policies.

\section{REGULATORY ASSETS}

After utility plant, regulatory assets comprise the utility's second major asset category. Regulatory assets refer to intangibles, such as deferred debt costs, that are considered assets because the costs are being collected in rates or because it is probable that the costs will be collected in future rates. Regulatory assets appear as deferred charges on a utility's balance sheet. Most regulatory assets appear on the balance sheet, but a few do not. As the Financial Accounting Standards Board (1982, p. 1) explains:

Regulators sometimes include costs in allowable costs in a period other than the period in which the costs would be charged to expense by an unregulated enterprise. That procedure can create assets (future cash inflows that will result from the rate-making process), reduce assets (reductions of future cash inflows that will result from the rate-making process), or create liabilities (future cash outflows that will result from the rate-making process) for the regulated enterprise.

Regulatory assets have taken an increasingly important role in the debate on industry transition costs because the potential costs are large, and in a competitive market these assets would have no value. In testimony before FERC, the Edison Electric Institute (EEI 1994) cites an estimate of

\footnotetext{
${ }^{5}$ These long-run contracts are primarily for coal. Utility purchases of natural gas or oil for electricity generation are frequently made under short-term contracts or on the spot market, though at least two California utilities have signed long-term contracts with natural gas suppliers (B. Wood, California Energy Commission, personal communication, September 27, 1995).

${ }^{6}$ The fuel adjustment clauses in place at many utilities are not directly relevant to the transition cost issues we discuss here. The balance in these clauses is in part determined by differences between forecasted fuel prices and fuel prices paid by the utility. These clauses are not intended to adjust for differences between the fuel prices paid by the utility and some indicator of the fuel's market price. Fuel adjustment clauses are relevant to transition costs if the recovery of fuel costs through the clauses is deferred, thereby creating a regulatory asset.
} 
$\$ 82$ billion for regulatory assets at investor-owned utilities at the end of 1993 . $^{7}$ Table 2 lists the accounts provided by EEI in descending order of account balance. The first five categories-deferred taxes ( $\$ 42$ billion); phase-in, synchronization, and other ( $\$ 18$ billion); unrecovered plant ( $\$ 6$ billion); unamortized loss on reacquired debt ( $\$ 5$ billion); and pensions and other post-employee benefits ( $\$ 3$ billion)_account for $\$ 74$ billion of the estimated $\$ 82$ billion.

Complete descriptions of all categories of deferred debits are provided in the Uniform System of Accounts (Code of Federal Regulations 1994). Below, we provide brief descriptions of the major regulatory assets identified by EEI.

- Deferred taxes are that portion of federal income taxes based on a utility's net income in a given year that are paid in later years. The utility is able to defer a portion of income tax payments during the initial years after a new construction project enters the rate base to reflect differences between book and tax depreciation. These depreciation differences do not affect the total amount of income taxes the utility pays but do affect when the payments are made to the U.S. Treasury. Utilities plan to recover the costs of deferred taxes through future rates when the tax costs are actually paid.

- The phase-in, synchronization, and other account are regulatory assets that reflect the costs of newly completed plants. Regulators may defer recovery of part of the costs of a new plant to reduce the immediate impacts of putting the asset in the rate base. Regulators may also defer costs that would otherwise be unrecovered due to differences between the time a new plant is completed and rates change to reflect recovery of necessary costs.

- Unrecovered plant costs consist of two categories. In the first category are the costs of studies ordered by regulators that did not result in construction. These studies include plant and site engineering analyses. The second category includes the costs of abandoned plant that was previously in service or under construction. The decision to abandon this plant, presumably made at the behest of or due to the direct order of regulators, results from decisions to shut down the plant prior to the end of its physical life or not proceed with plant construction.

- Unamortized loss on reacquired debt refers to losses incurred when debt is reacquired or redeemed. When long-term debt is reacquired or redeemed without being converted into another form of long-term debt, the loss is the difference between the amount paid upon reacquisition and the face value. When the reacquired debt is refunded, the loss is the difference between the amount paid upon refunding and the face value.

The balances of the remaining regulatory assets EEI identifies are comparatively small. We note that the account for decommissioning costs refers specifically to a program initiated by the Energy Policy Act of 1992 to assess utilities for the costs of decommissioning federally-owned

\footnotetext{
${ }^{7} \mathrm{EEI}$ notes that individual utilities may include items in these accounts that are not strictly regulatory assets. The accountants that prepared the estimates for EEI indicate that at least $\$ 75$ billion of the total are regulatory assets.
} 
uranium enrichment plants. Also, fuel costs and demand-side management (DSM) costs refer to deferred costs in existing balancing accounts, such as fuel adjustment clauses or special DSM surcharges, or, in the case of DSM, represent capitalized program expenditures.

The regulatory assets listed in Table 2 are included on utility balance sheets only because utility prices are set by regulators, prices are set to recover the cost of providing service, and it is probable that future revenue will recover these costs (Financial Accounting Standards Board 1982). In a competitive environment, these regulatory assets would not be supported by future revenue streams.

Because regulatory assets have no positive market value, the principles of asset valuation discussed in Chapter 2 are not relevant. Instead, the estimation issues center on determining which regulatory assets should be included as transition costs and then determining the balances in the relevant FERC Uniform System of Accounts (and other tracking accounts for regulatory assets that do not appear on the balance sheet). Some observers suggest that only generationrelated assets should be included as transition costs. Many of the specific categories listed in Table 2 are either dominated by generation-related costs or contain a substantial fraction of such costs. Others recommend that utilities should recover all costs from regulatory assets. Asset valuation approaches that rely on the difference between a utility's regulated rate and the market price for electricity to estimate transition costs must determine to what extent the costs of regulatory assets are already included in utility rates.

\section{PUBLIC POLICY OBLIGATIONS}

Because of their monopoly status, their connection with virtually every home and business in the country, and their impact on the economy and environment, electric utilities are vested with several public policy obligations. The abbreviated list of policy obligations in Table 2 is from Tonn, Hirst, and Bauer's (1995) more complete discussion. An important issue in the national debate on restructuring is that the past objectives of these programs may not be met in a more market-driven industry. Some have argued that these programs will also be stranded in the move to restructure the electric-utility industry.

While these obligations and their attendant benefits may indeed be at risk in a restructured industry, they are not transition costs in the same sense as the other categories discussed in this chapter. These other categories are costs that utilities will continue to incur in a restructured industry as a result of past utility, regulatory, or legislative decisions or policies and that have a defined recovery period. The costs of public policy obligations, in contrast, could be discontinued at any time by regulators or legislators. If legislators cancel low-income weatherization programs, for example, utilities will shortly stop incurring costs for these programs. In addition, these programs do not typically result in an accumulation of past costs.

Confusion about policy obligations and transition costs also stems from a misunderstanding about how costs are treated in the utility industry. For example, DSM expenditures that are capitalized are potential transition costs, but will be listed as a regulatory asset on the utility's 
balance sheet. In contrast, the ongoing DSM expenditures that a utility expenses (rather than capitalizes) are a policy obligation.

\section{OTHER ASSETS}

After utility-owned generation, the remaining net plant in service includes transmission and distribution assets. Most observers agree that transmission and distribution functions remain monopoly services that will continue to require government regulation of prices and services. As a result, the industry restructuring proposals under widespread discussion do not envision creating a competitive market for these services. Most observers agree that utilities will continue to recover costs for transmission and distribution assets and that these assets need not be included in transition cost estimates.

In contrast, Southern California Edison (SCE 1994) has argued that transmission and distribution assets could become stranded even if only generation is deregulated. SCE believes that if retail customers change service voltages, install self-generation, or combine multiple points of service to a single location, then previously used transmission and distribution facilities could become unneeded. Self-generation has always been a customer option and by itself has not involved special cost recovery treatment. The other two examples SCE raises can only be evaluated as they occur. Regulators, if disposed to consider the merits of such instances, may do so on a caseby-case basis.

\section{IMPLICATIONS FOR TRANSITION COST ESTIMATION}

An explicit consideration of cost categories has two implications for transition cost estimation. First, and most obvious, the more cost categories included as transition costs, the higher the estimated transition costs. It should be clear, for example, that including all regulatory assets will result in a higher transition cost estimate than if only generation-related assets are included. Even comparatively small components of rates can have substantial effects on transition cost estimates. As a simple example, consider a utility with embedded generation costs of $5 \notin / \mathrm{kWh}$ and an ROI (when expressed in $\notin / \mathrm{kWh}$ ) of $0.5 \notin / \mathrm{kWh}$. If this utility is faced with wholesale market prices of $2 \phi / \mathrm{kWh}$, its estimated transition costs can be either $3 \phi / \mathrm{kWh}(5 \phi-2 \phi)$ or $2.5 \phi / \mathrm{kWh}(5 \phi-0.5 \phi-2 \phi)-\mathrm{a}$ difference of $17 \%$.

Second, and perhaps less obvious, methods that rely on a comparison of utility retail price to market price will be affected by the costs that define these respective prices. Whether the cost categories need be strictly comparable depends on the objective of the estimation exercise. If the objective is to estimate transition costs associated with utility-owned generation, then it would be inappropriate to compare a fully bundled residential retail rate (containing generation, transmission, and distribution costs, among others) to a market price reflecting only generation. Such a comparison would clearly overestimate the transition costs associated with utility-owned generation. Thus, as we will see in Chapter 6 , even relatively simple top-down estimation approaches must take care to insure retail and market prices are structured appropriately for the comparison at hand. 


\section{CLASSIFICATION FRAMEWORK FOR DIFFERENT VALUATION APPROACHES}

We describe general valuation options using a classification framework initially suggested by SDG\&E (1994a). The classification framework consists of three categories, each with two elements: administrative versus market valuation; ex ante versus ex post valuation; and bottomup versus top-down valuation.

- Administrative valuation methods use forecasting, modeling, or other analytical techniques to determine the market and regulated value of utility assets and obligations.

- Market valuation uses auctions, sales, or asset spin-offs to determine the market value of assets (analysis may then be needed to compare market and regulated values).

- Ex ante methods are used before industry restructuring proposals are implemented.

- Ex post methods are used after these proposals are implemented.

- Bottom-up methods value assets individually.

- Top-down methods value asset portfolios.

The classification framework defines eight general valuation approaches. We describe these eight options in Appendix A. Tables 3 (administrative valuation) and 4 (market valuation) also list these eight general approaches and present the strengths and weaknesses of each. A shared strength of administrative approaches evident in Table 3 is that they include all relevant categories of assets and liabilities, although valuation of regulatory assets is done independently of other assets. Use of administrative approaches, however, may also require additional regulatory action to encourage utility mitigation of transition costs. Many regulators will not wish to allow utilities to continue to operate as if full recovery of all embedded costs is guaranteed.

As indicated by Table 4, market valuation approaches that use asset auctions or sales provide a clear indicator of value at the time of the sale. ${ }^{8}$ The timing of the sale will affect the market value; ex ante market valuation will yield different results than ex post market valuation. In addition, selling all generation assets at once will likely yield lower sale prices than selling assets in smaller amounts over a more extended time frame. Time is also an important consideration for

\footnotetext{
${ }^{8}$ The financial management field makes two important distinctions in the definition of asset value (see, for example, Weston and Brigham 1978). The amount realized from an asset sold separately from the organization that has been using it is known as the liquidity value. If an asset is sold as an operating business, the amount paid is called the going-concern value of the asset. Asset value as determined through sale or auction will thus be affected by whether the asset alone (the physical plant, for example) or the accompanying organization (the management and staft) is included as part of the sale.
} 
Table 3. Assessing different general administrative valuation approaches

\begin{tabular}{|c|c|c|}
\hline Approach & Strengths & Weaknesses \\
\hline $\begin{array}{l}\text { 1. Ex ante, bottom } \\
\text { up }\end{array}$ & $\begin{array}{l}\text { a. provides "up-front" estimate of } \\
\text { transition costs } \\
\text { b. includes all categories of assets } \\
\text { and liabilities } \\
\text { c. detailed analysis linking } \\
\text { transition costs to specific assets } \\
\text { (which reduces accounting } \\
\text { concerns by linking transition } \\
\text { costs to changes in book values } \\
\text { of specific assets) } \\
\text { d. may provide endogenous price } \\
\text { forecast (utility and market) } \\
\text { through market simulation } \\
\text { e. may capture dynamic response } \\
\text { of suppliers and customers to } \\
\text { changing market conditions }\end{array}$ & $\begin{array}{l}\text { a. data and computationally } \\
\text { intensive } \\
\text { b. careful data preparation } \\
\text { essential (e.g., danger of } \\
\text { double-counting costs) } \\
\text { c. may be difficult to understand } \\
\text { (many assumptions and } \\
\text { complex relationships) } \\
\text { d. agreeing on appropriate } \\
\text { assumptions will be difficult } \\
\text { e. response of market to } \\
\text { restructuring may be difficult to } \\
\text { predict } \\
\text { f. reliance on forecast creates } \\
\text { risks for utilities and ratepayers }\end{array}$ \\
\hline $\begin{array}{l}\text { 2. Ex ante, top } \\
\text { down }\end{array}$ & $\begin{array}{l}\text { la, } 1 \text { b above, plus } \\
\text { a. requires little data and simple } \\
\text { calculations (few assumptions } \\
\text { and simple relationships) } \\
\text { b. fewer assumptions to litigate }\end{array}$ & $\begin{array}{l}\text { 1e, If above, plus } \\
\text { a. aggregate analysis does not link } \\
\text { transition costs to specific } \\
\text { assets } \\
\text { b. relies on exogenous price } \\
\text { forecast (utility and market) }\end{array}$ \\
\hline $\begin{array}{l}\text { 3. Ex post, bottom } \\
\text { up }\end{array}$ & $\begin{array}{l}\text { lb, 1c above, plus } \\
\text { a. initial conditions known } \\
\text { (restructuring proposal } \\
\text { approved) } \\
\text { b. initial market response observed }\end{array}$ & $\begin{array}{l}\text { a. does not provide "up-front" } \\
\text { estimate of transition costs } \\
\text { b. delays valuation until market } \\
\text { maturity achieved (probable } \\
\text { conflict with accounting } \\
\text { practice) } \\
\text { c. developing market price indices } \\
\text { may be difficult }\end{array}$ \\
\hline $\begin{array}{l}\text { 4. Ex post, top } \\
\text { down }\end{array}$ & $1 b, 2 a, 3 a, 3 b$ above & $2 a, 3 a, 3 b$ above \\
\hline
\end{tabular}


Table 4. Assessing different general market valuation approaches

\begin{tabular}{|c|c|c|}
\hline Approach & Strengths & Weaknesses \\
\hline $\begin{array}{l}\text { 1. Ex ante, bottom } \\
\text { up }\end{array}$ & $\begin{array}{l}\text { a. provides "up-front" estimate of } \\
\text { transition costs } \\
\text { b. provides clear indicator of } \\
\text { market price at time of sale } \\
\text { c. provides clear changes in value } \\
\text { of specific assets } \\
\text { d. may resolve market power } \\
\text { concerns }\end{array}$ & $\begin{array}{l}\text { a. regulatory and market } \\
\text { uncertainty will affect market } \\
\text { value } \\
\text { b. does not address power- } \\
\text { purchase contracts and } \\
\text { regulatory assets } \\
\text { c. assets contributing to transition } \\
\text { costs are less marketable } \\
\text { d. ownership of certain assets } \\
\text { (hydro, nuclear) may be } \\
\text { difficult to transfer }\end{array}$ \\
\hline $\begin{array}{l}\text { 2. Ex ante, top } \\
\text { down }\end{array}$ & $\begin{array}{l}\text { 1a, } 1 \mathrm{~b}, 1 \mathrm{~d} \text { above, plus } \\
\text { a. possible to package less } \\
\text { desirable assets with more } \\
\text { desirable assets }\end{array}$ & $\begin{array}{l}\text { 1a, lb, 1c, } 1 \mathrm{~d} \text { above, plus } \\
\text { a. may not provide clear changes } \\
\text { in value of specific assets }\end{array}$ \\
\hline $\begin{array}{l}\text { 3. Ex post, bottom } \\
\text { up }\end{array}$ & $\begin{array}{l}\text { 1b, 1c, } 1 \mathrm{~d} \text { above, plus } \\
\text { a. regulatory and market } \\
\text { uncertainty reduced }\end{array}$ & $\begin{array}{l}\text { 1b, lc above, plus } \\
\text { a. does not provide "up-front" } \\
\text { estimate of transition costs } \\
\text { b. delays valuation until market } \\
\text { maturity achieved (probable } \\
\text { conflict with accounting } \\
\text { practice) } \\
\text { c. ownership of certain assets } \\
\text { (hydro, nuclear) may be } \\
\text { difficult to transfer }\end{array}$ \\
\hline $\begin{array}{l}\text { 4. Ex post, top } \\
\text { down }\end{array}$ & $1 b, 1 d, 2 a, 3 a$ above & $1 b, 1 c, 2 a, 3 a, 3 c$ above \\
\hline
\end{tabular}

market valuation approaches that rely on asset spin-offs to affiliated companies. In these cases, the stock price is one indicator of market value, but determining the appropriate time(s) to observe stock price may be difficult and contentious. Market valuation approaches also have the added potential benefit of addressing the market power concerns tied to several restructuring proposals. Selling a utility's generation assets to several smaller suppliers will promote greater competition. Unfortunately, not all assets potentially contributing to transition costs have market value. Regulatory assets are a prime example. Other assets, such as nuclear and hydropower 
facilities, have productive value, but concerns with future liability or transfer of ownership or operating licences may inhibit market interest. Liability concerns are particularly prominent for nuclear plants and center on long-term waste storage and plant decommissioning issues. An alternative to selling these assets is selling the electricity they generate. We examine this option in more detail in Chapter 6.

The distinction between ex ante and ex post options is time. All four general ex ante approaches could also be implemented ex post with appropriate changes to assumptions or procedures. The key strength of ex ante approaches is that they provide an early estimate of transition costs. As a result, suppliers and consumers can plan for the industry transition with these costs clearly established. The cost of acquiring this early certainty is the risk of being wrong. Ex ante administrative approaches that rely on a single estimate or single forecast of market price create potentially large risks for shareholders and ratepayers. Such approaches are untenable and suffer from the misuse of analysis and models as substitutes for, rather than guides to, decision making that contributed to many utilities' currently high embedded costs. Whether administrative or market valuation approaches are used, the difficult problem of anticipating the market response to a still undetermined industry and regulatory structure must be faced with ex ante methods. The important advantage of ex post options is that they resolve the uncertainty problem by delaying valuation until after industry restructuring is underway and a mature electricity market develops. Delaying valuation to this extent is unreasonable, however. Standard accounting practices and the financial markets may compel utilities to write off or mark down certain assets well before a competitive market matures.

Bottom-up options result in market values being assigned to individual assets. This feature addresses important accounting concerns; standard accounting practice requires that changes to book values be made for specific assets. In contrast, top-down approaches value overall changes to a portfolio of assets. Administrative bottom-up options also provide a wealth of information about the profitability of different assets or insights about the behavior of future markets. These details and insights come at the price of data intensiveness, computational complexity, and the attendant administrative difficulties associated with litigating numerous assumptions.

Administrative top-down approaches are easier to understand and implement. The opposite may be true for market approaches. Individual asset sales may be simpler to administer than asset portfolios or packages. Yet asset portfolios may make less desirable assets more marketable. For example, utilities might entice buyers to purchase a share of a nuclear plant by combining the share with a fully depreciated fossil plant. In addition, selling certain plants together may bring in more cash than selling them separately if certain positive synergies exist among the plants.

We could continue this general assessment, but the point is already clear, and the additional detail in Tables 3 and 4 reinforces the point: no single type of valuation approach is without a substantial weakness when the objective is to provide transition cost estimates that regulators authorize utilities to recover. For this important objective, combinations of these general approaches will be needed or solutions must be developed to address the weaknesses of any preferred approach. The more specific valuation approaches we reviewed suggest remedies for some of these weaknesses. 


\section{ASSESSMENT CRITERIA FOR SPECIFIC APPROACHES}

The eight assessment criteria we applied in our review of specific estimation approaches are defined in Chapter 5. We developed these criteria after considering the strengths and weaknesses of the general estimation approaches presented in Tables 3 and 4, and after reviewing the specific estimation approaches referenced in Table 5 (Chapter 6). We recommend that policymakers and analysts consider these criteria when reviewing transition cost estimates and estimation approaches. We believe implementation issues should be considered along with more technical issues, such as the determination of market prices.

Reasonable people could suggest additional criteria (or disagree with our current focus). We did not apply one important technical criterion, for example, because it did not surface as an explicit issue for most of the methods we reviewed. This is the issue of double-counting transition costs. A utility's high generation costs may be due to high depreciation expenses or high O\&M costs, for example. Above-market fuel-purchase contracts may also contribute to the high generation costs. If a transition cost estimation approach separately estimates the transition costs associated with generation and fuel contracts, the approach must control for the effects of high fuel costs on generation costs or risk double counting the contribution of fuel purchases.

\section{IMPLEMENTATION}

Implementation describes how valuation is conducted technically and procedurally. Administrative valuation methods typically are implemented by computer spreadsheet or computer model(s): Market valuation methods are implemented by auction, sale, spin-off, or some other market process. Implementation also refers to the need for regulatory proceedings to review estimates, estimation methods, or supporting data.

\section{ADMINISTRATIVE EASE}

From the regulator's perspective, administrative ease refers to the relative difficulty of implementing the approach and administering any associated proceedings. "High" administrative ease means the approach is simple and the amount of regulatory involvement in proceedings is comparatively slight. 


\section{PUBLICLY AVAILABLE DATA OR MODELS}

This criterion indicates whether the data or models necessary to calculate transition costs are publicly available or proprietary. A proprietary model may be available through licensing agreements or other commercial arrangements.

\section{RELEVANT ASSETS AND LIABILITIES}

This criterion has two dimensions. The first is whether the approach includes those assets and liabilities that many industry analysts agree should be included in transition cost estimates (see Table 2). The second is whether the approach actually includes those assets and liabilities it purports to include.

\section{TIME PERIOD}

This criterion refers to the time period included in the transition cost estimate. The time period differs depending on the level of aggregation in the analysis. For example, the time periods covered for utility generation and QF contracts often differ because the remaining lifetimes of undepreciated utility assets and contracts differ. The time period for an auction or sale refers to the duration of the sale process or the time elapsed between restructuring and the auction.

\section{PRICE (VALUE) DETERMINATIONS}

Price (value) determinations describe the approach used to determine market price or value. Market price determinations are made using either analytic techniques (price estimates-the basis for administrative valuation) or observing appropriate market indicators (which may also require analysis to yield an appropriate market price or transition cost estimate). Price estimates are developed endogenously or exogenously. Endogenous price estimates are an intermediate result of the analytic method used to calculate transition costs; these price estimates are not predetermined assumptions or externally imposed by the analyst, but are instead the result of market simulations or an analysis that explicitly accounts for the economics of plant dispatch in a region. In contrast, exogenous price estimates are derived directly from an assumption or an observation about the cost of different generation options. This estimate is then included as a key input in the transition cost estimate.

\section{PRICE (VALUE) COMPARISONS}

Transition cost approaches invariably involve a comparison of an asset's value under regulation to the same asset's market value. Parity refers to whether the regulated price and the market 
price are composed of comparable elements. Comparing a fully bundled residential retail rate to the levelized per unit output of new generation (e.g., a combined-cycle plant) is inappropriate if the objective is to estimate transition costs from the deregulation of generation. The fully bundled retail rate includes the cost of basic services such as generating capacity, energy supply, and power delivery as well as a host of ancillary services. Including these cost elements in the regulated price assumes that these services (and the asset value they represent) will all be potentially stranded by the move to deregulate generation. ROI indicates whether the regulated price includes an explicit return on investment. Including ROI in the analysis is not necessarily incorrect (the debate on this issue is still active), but including this assumption in the analysis does have a substantial effect on most transition cost estimates. Taxes indicate whether the effects of income taxes are included in the approach. As noted in an earlier report (Baxter and Hirst 1995), a dollar revenue loss to the utility does not translate as a dollar loss to shareholders because the utility does not have to pay federal, state, or local income taxes on the lost revenue. 9 Of the 1.2 other administrative valuation approaches we reviewed, only one (SCE 1994) mentions the need to adjust estimates for the effects of taxes.

\section{MARKET DYNAMICS}

Utility actions and the actions of the larger marketplace will affect transition costs. Market dynamics refers to the extent that estimation approaches reflect at least some of those effects. For example, high-cost utilities will respond to increased competition by lowering costs. Many utilities will pursue previously protected markets to increase sales. Both these effects will affect the transition costs that utilities ultimately face. Similarly, the wider marketplace will also respond to increased competition. Over time, electricity prices will change. These changes should lead to short-run and long-run changes in demand. Should current capacity surpluses tighten, prices should rise thus stimulating development of new supplies. The interaction of demand and supply over time will in turn determine future market prices, which directly affect transition costs.

${ }^{9}$ Any losses experienced by utility stockholders are shared with taxpayers. If the utility's average income tax rate is $35 \%$, then utility shareholders pay for only $65 \%$ of the transition costs. Thus, the shareholder loss is (1utility tax rate) of the net revenue loss to the utility. See Baxter and Hirst (1995) for a detailed illustration of the effects of income taxes on transition cost estimates. 



\section{ASSESSING VALUATION METHODS AND APPROACHES}

In Chapter 6, we identify 15 specific valuation approaches and provide detailed descriptions and assessments of seven of these approaches. Chapter 6 concludes by suggesting which general approaches may be suited for particular estimation applications.

\section{VALUATION APPROACHES REVIEWED AND ASSESSED}

To be eligible for review, a valuation approach must be described in publicly available documents. In the one case where the approach is not publicly documented, the developers provided us with a working knowledge of their approach comparable to that we acquired for the other approaches. Table 5 lists the 15 approaches to estimating tranisition costs that we reviewed and places these approaches within our general classification framework. We have not identified any explicit ex post approaches, though we reiterate that any of the ex ante options could be implemented ex post with appropriate changes in assumptions or procedures. We identified few detailed market valuation options specific to U.S. restructuring proposals.

We selected seven of these proposals for more detailed description and assessment (see the italicized listings in Table 5). These descriptions are found in Appendix B. We attempted to select specific approaches that are representative of a general approach or have features of particular interest. Four of the approaches represent proposals for actual cost recovery (CPUC, FERC, Maine Public Utilities Commission, and Pacific Gas \& Electric) while the remaining three approaches are focused on national transition cost estimates or industry-wide issues (Moody's Investor Services, Resource Data International, Sant and Naill).

Though still incomplete, the CPUC (addressing retail transition costs) and FERC (addressing wholesale transition costs) proposals are included because both have attracted widespread national attention. The transition costs developed by Moody's Investor Services also attracted widespread attention. A unique feature of Moody's approach is the use of transparent techniques to estimate market prices for capacity and energy that comport with economic principles and market realities. The Maine Public Utilities Commission (MPUC) proposal, while no longer active, is a much more specific example of an option states might pursue. Pacific Gas \& Electric Company (PG\&E) offers a well-documented example of the top-down approach, with the added feature that utility-owned generation is assessed separately from power-purchase obligations. The PG\&E proposal, developed in response to CPUC direction that utilities file transition cost estimates, is one of the few publicly available transition cost estimates generated by a utility. The Resource Data International, Inc. (RDI) approach is an example of a bottom-up approach that features market prices estimated using market simulations. Sant and Naill is a prominent example of a market valuation approach. Table 6 highlights our assessment of these seven different estimation approaches. 
Table 5. Different approaches to estimating transition costs (italicized approaches are assessed individually) ${ }^{1}$

\begin{tabular}{|c|c|c|}
\hline & Administrative valuation & Market valuation \\
\hline & Ex ante & Ex ante \\
\hline Bottom-up & $\begin{array}{l}\text { Barkovich (1994) } \\
\text { CPUC (1995) } \\
\text { Moody's }(1995) \\
\text { RDI }(1994 a, b) \\
\text { Rudden }(1994)\end{array}$ & $\begin{array}{l}\operatorname{IEP}(1994)^{2} \\
\text { Sant and Naill (1994) }\end{array}$ \\
\hline Top-down & $\begin{array}{l}\text { Baxter and Hirst (1995) } \\
\text { CEC (1994) } \\
\text { CPUC (1995) } \\
\text { FERC (1995) } \\
\text { MPUC (1995) } \\
\text { NYPSC (1994) } \\
\text { PG\&E (1994a,b) } \\
\text { SCE (1994) } \\
\text { SDG\&E (1994b) }\end{array}$ & $\begin{array}{l}\operatorname{IEP}(1994)^{2} \\
\text { Sant and Naill }(1994)^{2}\end{array}$ \\
\hline
\end{tabular}

1.We did not identify any explicit ex post approaches, which explains that method's absence from the table.

2. According to these proposals, valuation could include individual assets or groups of assets. Thus, these approaches can be implemented as either bottom-up or top-down methods.

Abbreviations: $\mathrm{CEC}=$ California Energy Commission; $\mathrm{CPUC}=$ California Public Utilities Commission; FERC = Federal Energy Regulatory Commission; IEP = Independent Energy Producers; Moody's = Moody's Investor Service; MPUC = Maine Public Utilities Commission; NYPSC = New York Public Service Commission; PG\&E = Pacific Gas \& Electric Company; RDI = Resource Data International, Inc.; Rudden = R.J. Rudden Associates, Inc.; SCE = Southern California Edison Company; SDG\&E = San Diego Gas \& Electric Company.

\section{REVIEW OF SPECIFIC ESTIMATION APPROACHES}

\section{California Public Utilities Commission}

The major outlines of the CPUC's preferred approach are clear, but the current proposal still leaves many specific issues unresolved (CPUC 1995). The CPUC's proposal also holds open the possibility for utility divestiture of generating assets and the use of a market valuation approach to establish transition costs. The proposal, however, does not direct the utilities to divest. If the 
utilities do not sell or spin off their generating assets, the CPUC proposes to use an administrative valuation approach.

This proposal rejects the approach the CPUC previously suggested, which was to conduct a onetime, bottom-up, ex ante administrative valuation (CPUC 1994b). The CPUC is now proposing an approach that relies on a comparison of regulated utility prices to observed market prices. This comparison could take several forms. For example, utilities might make a prospective oneyear forecast of transition costs, based on assumptions about utility revenues and market prices for the coming year. This forecast will subsequently be reconciled to observed utility revenues and market prices. The difference between forecasted and observed transition costs will be reflected as an adjustment (either positive or negative) in the next year's transition costs forecast. Alternatively, the CPUC might direct utilities to develop an annual retrospective estimate of transition costs based on observed revenues and market prices from the previous year. The CPUC may also elect to use longer intervals than a year between transition costs forecasts and subsequent reconciliations. Thus, once the estimation approach is clearly established and the cost recovery mechanism is developed, transition cost recovery may well resemble other types of cost recovery mechanisms (such as the energy cost adjustment clause) used by the CPUC.

The CPUC has not decided on whether to use a bottom-up or top-down valuation approach. The top-down approach is easier to implement. The administrative ease for either approach will be reduced if an annual proceeding is needed to determine the appropriate data and methods to estimate transition costs. An important issue under either a bottom-up or top-down approach will be identifying and agreeing on suitable indicators of market prices. Because the CPUC's administrative valuation method is not fully specified, we cannot determine whether parity exists between the utility retail price and the appropriate market price. Should a suitable market price indicator be found and used in the transition cost estimate and some type of reconciliation or ex post approach be used, then important market dynamics will be included in eventual transition cost estimates. These dynamics include the interaction of demand and supply to determine observed market prices. It is not clear that the utilities' operational response to market dynamics will be reflected in the transition cost estimates. ${ }^{10}$ As a result, utilities may require incentives to cut costs, market surplus energy, and mitigate potential transition costs over time. Whether the utility response to market dynamics is reflected in the transition cost estimates depends in part on the nature of the price comparison. This problem is of greater concern if utilities' retail rates, as defined under cost-of-service regulation, are used to indicate what utility prices and anticipated revenue recovery should be.

\section{Federal Energy Regulatory Commission}

FERC's estimation approach addresses transition costs arising from its implementation of nondiscriminatory transmission access by public utilities (FERC 1995). FERC's preliminary

\footnotetext{
${ }^{10} \mathrm{The}$ CPUC intends to move from cost-of-service regulation to performance-based rate making, which will provide incentives for utility efficiency gains. The CPUC (1995) plans to decide at a later time how performancebased rate making will affect the estimation and collection of transition costs.
} 
Table 6. Assessing specific approaches to estimating transition costs

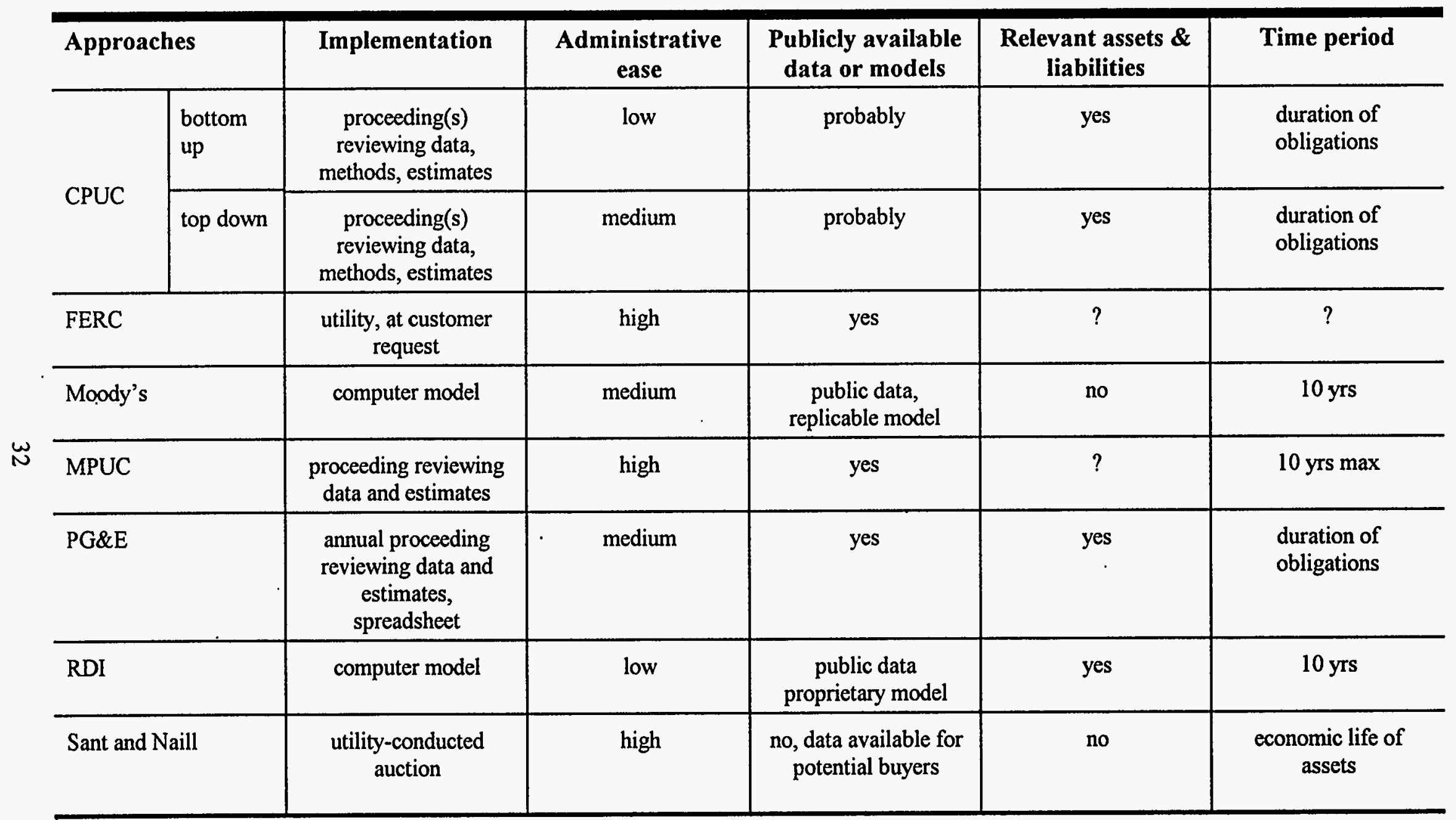


Table 6 continued

\begin{tabular}{|c|c|c|c|c|c|c|c|c|c|}
\hline \multicolumn{2}{|c|}{ Approaches } & \multicolumn{3}{|c|}{ Price determinations } & \multicolumn{3}{|c|}{ Price comparisons } & \multicolumn{2}{|c|}{ Market dynamics } \\
\hline & & \multicolumn{2}{|c|}{ Estimate } & \multirow[t]{2}{*}{ Market } & \multirow[t]{2}{*}{ Parity } & \multirow[t]{2}{*}{ ROI } & \multirow[t]{2}{*}{ Taxes } & \multirow[t]{2}{*}{ Utility } & \multirow[t]{2}{*}{ Market } \\
\hline & & Endogenous & Exogenous & & & & & & \\
\hline \multirow{2}{*}{ CPUC } & bottom up & & . & yes & $?$ & yes & $?$ & $?$ & yes \\
\hline & top down & & & yes & $?$ & yes & $?$ & $?$ & yes \\
\hline \multicolumn{2}{|l|}{ FERC } & $?$ & $?$ & $?$ & $?$ & $\mathrm{~N} / \mathrm{A}$ & no & $?$ & $?$ \\
\hline \multicolumn{2}{|c|}{ Moody's } & yes & & & yes & no & no & no & $\begin{array}{l}\text { yes (ST) } \\
\text { no (LT) }\end{array}$ \\
\hline \multicolumn{2}{|l|}{ MPUC } & & yes & & $?$ & yes & no & $\begin{array}{c}\text { yes } \\
\text { (arbitrary) }\end{array}$ & $\begin{array}{c}\text { yes } \\
\text { (arbitrary) }\end{array}$ \\
\hline \multicolumn{2}{|l|}{ PG\&E } & & $\begin{array}{c}\text { yes } \\
\text { (initially) }\end{array}$ & $\begin{array}{l}\text { reconcile } \\
\text { to market }\end{array}$ & yes & yes & no & yes & yes \\
\hline \multicolumn{2}{|l|}{ RDI } & yes & & & yes & yes & no & $\begin{array}{l}\text { yes (ST) } \\
\text { no (LT) }\end{array}$ & $\begin{array}{l}\text { yes (ST) } \\
\text { no (LT) }\end{array}$ \\
\hline \multicolumn{2}{|c|}{ Sant and Naill } & & & yes & yes & $\mathrm{N} / \mathrm{A}$ & N/A & $\begin{array}{l}\text { yes (ST) } \\
\text { yes (LT) }\end{array}$ & $\begin{array}{c}\text { no }(\mathrm{ST}) \\
\text { yes (LT) }\end{array}$ \\
\hline
\end{tabular}

Abbreviations: CPUC = California Public Utilities Commission; FERC = Federal Energy Regulatory Commission; LT $\Rightarrow$ long term; Moody's = Moody's Investor Service; MPUC = Maine Public Utilities Commission;; N/A = not applicable; PG\&E = Pacific Gas \& Electric Company; RDI = Resource Data International, Inc.; ROI = return on investment; ST = short term; ? = undecided or not possible to determine. 
findings favor a top-down administrative valuation approach. The essence of FERC's approach is a comparison of a utility's wholesale rate with a wholesale market price to estimate the expected utility revenues lost due to a departing customer. The approach is intended to address specific cases when individual wholesale customers decide to switch suppliers or when retail customers become wholesale customers. Further, the approach is consistent with FERC's desire to directly assign transition costs to the departing wholesale customer. The transition cost estimate is developed by the utility, at the customer's request, or the utility must provide the customer with the formula the utility would use to estimate transition costs. The estimate is intended to represent the customer's maximum possible transition-cost exposure. We note that this maximum exposure estimate is unlikely to reflect the costs utilities will ultimately recover. First, FERC emphasizes the need for utilities to act to reduce transition costs (such as marketing excess energy supplies). Second, FERC strongly encourages utilities and existing customers to resolve transition cost issues through negotiated exit fees or amendments to existing contracts. That the utility "would only be able to seek stranded cost recovery according to the formula and other terms identified in its earlier discussions with the customer" (FERC 1995, p. 196) provides the utility an incentive to reach agreements with its customers: before FERC, the utility would be faced with an "all or nothing" decision on cost recovery.

Many important aspects of FERC's estimation approach are unresolved. These aspects include estimating what revenues the utility would have received had the departing customer remained with the utility, estimating the market value of the energy the utility would have sold to the departing customer, accounting for utility mitigation measures, establishing a reasonable compensation period, and determining what costs are not fully reflected in current requirements rates. Until these issues are resolved, it is not possible to offer any specific assessment on what assets and liabilities are included, the compensation period, price determinations, or market dynamics. FERC's proposed approach will be relatively easy to administer unless FERC establishes a separate account to track utility mitigation efforts. In addition, the methods and assumptions used by the utility will be available to the affected customer in all cases and, in the case of an unresolved dispute between the utility and customer, will be publicly available in a FERC proceeding. We also cannot comment on whether the utility wholesale price and market wholesale price are constructed comparably. Nowhere does FERC acknowledge the effect of income taxes on transition cost estimates. As a result, we assume that FERC's proposed approach will not include this tax effect, which, considered in isolation, will lead to higher estimates of transition costs.

\section{Moody's Investor Service}

-Moody's (1995) uses an administrative, ex ante, approach to develop national estimates of transition costs for the major investor-owned electric utilities. The expression Moody's uses to estimate transition costs resembles the general top-down formulation, but Moody's approach is ultimately closer to a bottom-up method. In addition, the approach uses plant-specific data to estimate market prices and transition costs for each of the nine North American Electric Reliability Council (NERC) regions. Moody's approach is unique in two respects: first, the 
market price estimates for capacity and energy are derived from transparently constructed supply curves and second, the approach is motivated by the concept of a "break-even price" for capacity.

Moody's estimates transition costs as the product of a utility's total capacity and the difference between a utility's break-even price for capacity, adjusted for purchased power and regulatory assets as necessary, and the regional market price of capacity. This estimate is rooted in Moody's assumption that a utility unable to recover all its fixed production costs through energy sales will have to charge for capacity (Moody's 1994a, b). The break-even price is the amount a utility must charge for capacity to insure recovery of all fixed production costs, assuming the sale of $100 \%$ of its capacity. Any margins the utility earns through energy sales are applied to fixed costs. The greater these margins, the lower the capacity charge need be for the utility to recover its fixed costs, or "break even."

A key feature of Moody's approach is the estimation of market prices for capacity and energy. Moody's derives both estimates using the same conceptual analysis-by constructing supply curves for capacity and energy in each region and then estimating the average demand for these two services. The supply curves are based on the cost characteristics of the generating plants in a NERC region. Moody's defines the market price for capacity as the marginal cost of the most expensive unit needed to satisfy forecasted demand (including a reserve margin) in each region. Moody's defines marginal cost as a plant's nonfuel O\&M, less the margin the plant earns, if any, from selling energy above its variable costs. In estimating market prices for capacity, Moody's examines NERC's regional forecasts of supply and demand for the 1995-2004 interval. For those years when a region's reserve margin falls below 15\%, Moody's assumes the market price equals the cost of a new gas-fired, combined-cycle combustion turbine. The market price Moody's uses in its analysis is a ten-year average of these single-year estimates

Moody's defines the market price for energy as the variable production cost of the most expensive plant producing energy at the average level of demand in a region. Individual plants form points on the supply curve in order of increasing cost. Average demand is the total production of all plants in a region divided by 8,760 - the number of hours in a year. Changes in the average demand for energy will result in different market prices for energy, different breakeven prices, and different transition cost estimates.

Moody's approach represents a middle ground between the simple top-down approaches and the more complex bottom-up methods. Like other bottom-up approaches, Moody's attempts to reflect the effects of regional supply and demand conditions on market prices, but does so using a transparent approach. The inarket price estimates embody basic utility economics principles and market realities - individual plants are dispatched in order of increasing variable costs and the value of capacity depends on existing and anticipated capacity balances in each region. While the approach is transparent, it is also clearly more difficult to implement than one that simply assumes a market price based on recent observations in the wholesale market or the estimated costs of supply. 
We cannot assess whether Moody's assumption that a future electricity market will value both energy and capacity is reasonable. More importantly, we do not believe that the robustness of this assumption, while a critical motivator of Moody's estimation approach, is strongly linked to the robustness of the resulting estimates. Moody's is attempting to measure the most relevant costs affected by the further deregulation of generation: fixed production, power purchases, and regulatory assets. The distinguishing feature of Moody's approach is the focus on cost recovery through both $\mathrm{kW}$ and $\mathrm{kWh}$ sales rather than solely from $\mathrm{kWh}$ sales, as with other administrative valuation methods. The approach's basic formulation focuses on estimating a utility's potential unrecovered fixed costs when competitive markets set prices for generation services, as are virtually all the administrative valuation approaches we reviewed for this study.

A possible shortcoming of Moody's approach is the use of averages to simplify the analysis. Use of average demand to estimate an average market price for energy is a simplification of operating conditions. When demand exceeds the average demand, plants with variable production costs above the average market price can operate at a profit. Conversely, when demand falls below the average, plants with variable production costs below the average market price can operate at a loss. If hourly demand is distributed symmetrically around this average, then the differences will cancel.

Moody's conducted a sensitivity analysis on the combined effects of different demand levels and demand durations on a utility's break-even price (Moody's 1994b). The results suggest Moody's use of the average demand overestimates the average market price and, as a result, underestimates break-even prices for capacity. The effect of varying demand is proportionally much greater for utilities with comparatively low initial estimates of break-even prices. Thus, utilities with the greatest potential for transition costs are the least sensitive to changes in average demand.

Moody's use a of ten-year average capacity price probably overstates the current market price for capacity because most regions in the United States currently have capacity surpluses (NERC 1995). The assumption that regions will maintain $15 \%$ reserve margins as markets become more competitive may also be generous. If lower reserve margins are tolerated, then capacity prices will remain lower, which will lead to higher transition cost estimates.

We note that Moody's does not include fuel-purchase contracts in the transition cost estimate. In addition, the price comparisons used to estimate transition costs do not include ROI or tax effects, but the break-even and capacity prices are comparably constructed. Finally, Moody's makes no assumptions about the effects market forces may have on future utility costs or how alternate suppliers and consumers might respond to changing market conditions over time.

\section{Maine Public Utilities Commission}

MPUC initiated a rulemaking on the recovery of transition costs due to either the authorization of new electric utilities to provide service in an existing utility's current service area or the departure of an existing customer from a utility's nonexclusive service territory where the utility 
currently providing service had a demonstrable expectation that service would continue (MPUC 1995). The MPUC subsequently withdrew its proposal to prevent jurisdictional conflicts with FERC (1995).

The MPUC estimation approach is a top-down, ex ante administrative valuation method. The utility will provide an initial estimate of transition costs by rate element (any individual charge in the rate schedule used to calculate customer bills, such as an energy charge or a demand charge) within each customer class (expressed as dollars per $\mathrm{kWh}$ or $\mathrm{kW}$ ). The initial estimates are the difference between the utility's embedded costs and its marginal costs for the services no longer provided to departing customers, adjusted by a mitigation factor of 0.5 . These initial, generic, estimates will be reviewed in a proceeding and revised if necessary. The generic estimates, when approved by the MPUC, will only be revised if the approved estimates differ from existing estimates by $20 \%$ or more on a present value basis over the remainder of the transition period. The generic estimates will be the basis for the calculation of actual exit fees for customers departing the utility system. The exit fee will be the generic per unit transition costs for the years remaining in the transition period multiplied by the average use per customer class (or, in some cases, by the departing customer) over the previous three years.

The MPUC approach would be easy to administer, especially because the basic transition cost estimate is calculated in a single proceeding and need not be revisited unless a revised estimate exceeds a specified threshold. The review of these initial estimates in a public proceeding helps ensure that the data and methods used to develop the estimates will be subject to broad examination. We are not certain whether the MPUC approach would include all relevant assets and liabilities. This depends on how the utility marginal cost estimate, critical to the determination of transition costs under this approach, is constructed. For example, if the utility marginal cost estimate includes only utility production costs, and not the marginal costs associated with long-term firm power purchases, then all long-term firm power purchase costs would be included in the utility's transition cost estimate. Use of a properly calculated utility marginal cost has the benefit of sending a price signal to customers that will discourage uneconomic bypass of the utility's system. The MPUC proposal does not address the effects of taxes on utility transition costs. Market dynamics are addressed albeit through the imposition of an arbitrary mitigation factor. Because this mitigation factor is applied immediately, the utility is furnished a strong incentive (or burden, depending on one's perspective) to immediately cut costs or market the surplus energy elsewhere, or both. The time period covered by the analysis is the earlier of ten years or the time at which projections indicate a convergence of utility embedded and marginal costs.

\section{Pacific Gas \& Electric Company}

The PG\&E (1994a,b) approach is a top-down, ex ante, administrative valuation method that broadly resembles the top-down approach suggested by the CPUC. Both PG\&E and the CPUC call for a short-term transition cost forecast based on projections of utility revenues and market prices. The short-term forecast is subsequently reconciled to observed utility revenues and market prices, with the difference between forecasted and observed transition costs (whether 
positive or negative) reflected in the utility's transition cost recovery charge for the next period. Thus, both PG\&E and the CPUC foresee a regular proceeding to reconcile previous transition cost forecasts and to present forecasts for the upcoming period. The need for frequent proceedings, unless carefully designed, will increase the administrative burden on regulatory commissions relative to a one-time administrative valuation.

PG\&E's estimation approach has at least three interesting features. First, PG\&E separately assesses the contributions of utility-owned generation, $\mathrm{QF}$ contracts, and regulatory assets to total utility transition costs. The PG\&E approach demonstrates the use of a top-down valuation method that links transition costs to different major asset categories. This approach stands in contrast to more aggregate top-down methods, such as Baxter and Hirst (1995), that result in a single transition cost estimate for the utility's entire asset portfolio. Second, PG\&E's market price forecast is developed from separate forecasts of fixed and variable cost components, recognizing that capital costs and fuel costs do not contribute equally to total costs and may not change at the same rates. Third, PG\&E's forecast of the contribution of regulatory assets is based on the annualized change in recent year-end account balances.

PG\&E relies on publicly available data to estimate transition costs. While tracing certain elements of the calculation (such as the generation forecast, which PG\&E takes from a recent rate case filing) to materials filed in other proceedings is cumbersome and time consuming, it is a task familiar to regulatory staffs that regularly review utility filings. PG\&E's estimation method is well documented in its testimony and supporting workpapers (PG\&E 1994a, b). The method includes all relevant categories of assets and liabilities. Plant decommissioning expenses are treated as an ongoing public policy obligation that will continue beyond the transition to a new industry structure. These decommissioning costs are not included in PG\&E's transition cost estimates. PG\&E recommends that decommissioning costs be recovered using a separate charge (which may also include costs for other public policy obligations) that is applicable to all electricity users. Like the CPUC, PG\&E recommends that transition costs be calculated for the duration of the underlying obligations. PG\&E estimates these time periods as 20 years for utilityowned generation and regulatory assets and 31 years for certain power-purchase obligations. The market price is initially determined exogenously but will be reconciled to some observed market price benchmark during each reconciliation. The utility's embedded generation costs and the market price contain comparable cost categories, though the base revenue requirement for generation contains an explicit ROI. PG\&E does not raise the issue of taxes in its testimony, and the transition cost impacts are not adjusted for the effects on income taxes.

The transition cost estimates that PG\&E presents do not reflect market dynamics. PG\&E's reconciliation process, however, will include the market dynamics implicit in market prices. PG\&E does not appear to include the effects of any utility response to the market in this reconciliation process, such as utility price reductions through cost savings or pursuing new markets for sales. PG\&E is proposing that generation revenue be set through a performancebased rate-making mechanism that should provide the utility incentives to lower costs (D. Hall, PG\&E, personal communication, September 8, 1995). 


\section{Resource Data International, Inc.}

The RDI (1994a,b) approach is an example of a bottom-up, ex ante, administrative valuation method. The Inter-Regional Electric Market Model (IREMM) is at the heart of the RDI approach (Coste and Adams 1994). IREMM has two primary features. First, the model has a production cost feature that simulates utility system operation, including unit dispatching, maintenance scheduling, and cost accounting. The production cost feature operates at the unit level for all investor-owned utilities and the largest municipal utilities in the continental United States; the production cost analysis includes both utility- and non-utility-owned generation. Second, IREMM estimates market prices for each utility and identifies the energy transactions that result from the interaction of supply and demand for energy in the wholesale market. IREMM simulates the operation of a competitive wholesale market where each utility attempts to maximize its profits on sales or its savings on purchases (or both). The objective of IREMM's wholesale market simulation is to maximize the economic benefits of these profits and savings over all utilities, subject to the constraints of supply, demand, and the transmission system.

RDI estimates transition costs as the net present value of the stream of future fixed costs in excess of future operating revenue. For utility-owned generation, IREMM tracks the annual generation for each utility's units (to serve native loads or for sales to the wholesale market) and the prices obtained for that generation. The product of generation and price yields the operating revenue provided for each unit. The sum of the differences between operating revenues, net of variable production costs, and fixed costs for each utility's units indicates whether the utility's portfolio is able to provide revenue sufficient to recover its fixed costs. The revenue shortfalls contribute to transition costs.

Transition cost estimates for utility power-purchase contracts are developed in much the same manner, except that the utility's revenue obligations are defined by the payment and delivery terms of the contracts. RDI uses IREMM's monthly wholesale price estimates by time period to estimate a weighted annual average market price. Any difference between the revenue obligations defined by the contract and the market value of the purchased power contributes to transition costs. RDI conducts a similar analysis for utility obligations for long-term coal purchase contracts. For regulatory assets, RDI reports the balances currently carried on utility books, as reported to FERC.

The RDI method has the strengths characteristic of a bottom-up approach. RDI provides a detailrich analysis based on the operating performance and economic attributes of individual generating units. As a result, the method is able to link transition costs to specific generating assets. The RDI method also relies on an endogenous estimate for market price rather than an exogenous estimate or assumption. This price is derived from a market simulation of essentially the entire interconnected electricity generation system. In addition, the market price estimate begins to reflect the time-varying nature of electricity prices; within each of 61 energy markets, market prices are estimated monthly for three time periods (on-peak, mid-peak, and off-peak). The RDI approach is also comprehensive, including all relevant categories of assets and liabilities. 
As with the top-down approaches, the strengths of a detailed bottom-up analysis are accompanied by certain weaknesses. The nature of the simulation problem requires a sophisticated modeling tool. IREMM is not transparent and may be difficult for regulators to apply in the context of public proceedings to address transition costs. In addition, the details of the simulation require numerous assumptions about unit operating performance and costs, including heat rates, O\&M costs, and maintenance schedules, as well as assumptions about future demand growth and supply requirements. The amount of detailed data needed to implement the method suggests increased opportunities for disagreements and attendant litigation about the appropriate assumptions to estimate transition costs. Use of such a model for regulatory determinations of transition costs will impose difficulties, both in terms of data development and maintenance and also implementation of the approach in a regulatory setting.

The assessment of utility operating revenues and generation cost obligations appears to be based on comparable price or cost elements. Thus, the market price for generation is a wholesale price net of transmission charges, and the cost of utility generation includes both fixed and variable costs. The fixed cost component for utility generation includes an explicit ROI. The RDI approach, like all those reviewed in detail, does not consider the effects of income taxes on transition costs. IREMM appears to partially reflect the effects of short-term markets. Utilities respond to market price signals to determine whether they become buyers or sellers on the wholesale market. This simulated market includes the effects of indirect transactions, that is, transactions between two systems separated by intervening companies through which the power must be wheeled. It does not appear, however, that potential long-term market dynamics are reflected. Future demand and supply are taken as exogenous assumptions as are a utility's future operating performance and costs. Thus, the RDI approach does not consider how future demand and supply might respond to changing prices and costs as a result of a more competitive environment.

\section{Sant and Naill}

Sant and Naill (1994) propose a market valuation approach designed to provide a guaranteed market for the electricity generated by divested assets and to address other industry restructuring issues. The generating assets will be divested through a public offering or through a spin-off. Any auction or sale will be conducted by the utility and could include individual assets or packages of assets. Utility-affiliated generating companies could participate in the auction if the parent company had spun off the affiliate so that no association existed between the affiliate and the parent company.

Sant and Naill include two important conditions on the asset sale. First, the selling utility will be guaranteed at least book value for the asset. Second, prospective buyers will be offered a fixedprice contract from the utility for the electricity generated over the rest of the asset's economic life. The fixed-price contract includes the remaining undepreciated capital costs for the asset, including an ROI, fuel costs, and nonfuel O\&M costs. Based on these costs, the utility calculates a rate schedule that includes a $5 \%$ reduction in the overall rate needed to recover the above costs. The $5 \%$ rate reduction represents potential cost savings from reducing capital costs, fuel costs, or 


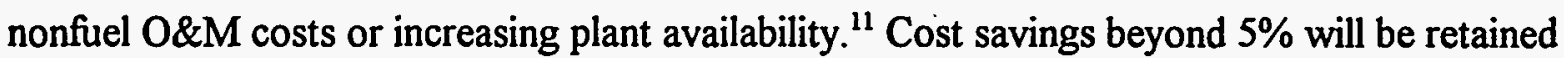
by the new owners of the assets. At the end of the contract, asset owners negotiate new contracts at competitive market prices or sell electricity on the spot market. Thus, the Sant and Naill approach encourages utility divestiture, provides asset purchasers with a long-term guaranteed market (and the prospects for higher profits through cost savings), and offers ratepayers the guarantee of at least a modest reduction in their current rates. Certain questions, however, such as which entity bears the risk of plant outages or changes in electricity demand, are left . unaddressed. These questions would have to be resolved before the fixed-price contract was completed.

Because the utility is conducting the auction and calculating the rates or terms of the long-term power purchase, the administrative obligations of regulators are limited to oversight and review. The auction and fixed-price contract effectively transfer the utilities' transition costs to the asset purchasers. The auction provides a measure of market value at the time of the sale only if the highest bid is above the asset's book value. This constraint on the minimum sale price, which is necessary to transfer the associated transition costs, creates an asymmetrical auction where market values will only be revealed when market values exceed book values. Assets with these latter characteristics do not contribute to transition costs. A general problem with the auction approach to transition costs is that the assets contributing to the problem almost by definition have the least desirable market characteristics.

Sant and Naill recognize this problem and suggest that one solution is packaging competitive and less competitive plants (or portions of plants). For packaged assets, the utility will presumably be guaranteed recovery of their total book values. Sant and Naill do not suggest, however, what makes such a guarantee possible or who would enforce such a guarantee. The proposal also captures several aspects of market dynamics. The new asset owners have incentives to reduce generating costs in both the short term and long term. Over the long term, all asset owners will be exposed to the market forces that will encourage competitive long-run marginal generation costs. These competitive forces will be muted in the short run, however, because the proposal delays the onset of full retail competition until the guaranteed contracts expire. This delay will differ, perhaps greatly, among utilities because it is tied to the economic depreciation schedules of individual assets. Some depreciation schedules may extend beyond what will be acceptable to structure a contract. In addition, Sant and Naill recognize that a nationwide sale of generation will be difficult and might depress bid prices. As a result, they recommend conducting auctions on a state-by-state basis over ten years or more. But because full retail competition will be delayed until the contracts awarded as a condition of the auction expire, this suggests that markets will not see retail competition for many years. This delay will not be a problem for states where retail competition is not a primary objective.

Nuclear plant auctions require additional features. For example, Sant and Naill suggest that nuclear plant buyers may require federal insurance protection to guarantee waste disposal and decommissioning costs. Unlike other plants, the selling utility might have to bid on its own

\footnotetext{
${ }^{11}$ Sant and Naill use the 5\% figure as an illustrative value. The actual figure will depend on the potential for cost savings from operating the generating assets in a competitive environment.
} 
nuclear units. In the absence of other bids, the plants remain with the utility. Alternatively, the utility could sell the output from the plants, rather than the plants themselves, under long-term contracts to electricity distributors or individual customers. Even with these provisions, the existence of a market for nuclear units is highly uncertain. Kahn (1994) argues that no such market exists and that the nuclear industry must be nationalized. The disposition of nuclear assets is a key issue if, as some have argued, these assets are a major contributor to utility transition costs (Yokell, Doyle, and Koppe 1995).

Sant and Naill also recommend retiring plants with long-run operating costs that exceed long-run marginal costs of generation. They argue that most of these high-cost plants will be nuclear and that regulations allow utilities to fully recover the book value of these assets. If their assertion is correct, then a meaningful portion of nuclear capacity would be retired. The remaining economic nuclear plants may be more attractive to potential purchasers, particularly with the insurance guarantees.

An important shortcoming of the auction approach is that it only deals with utility generation and not long-term firm purchase obligations and regulatory assets. Sant and Naill's proposal is also silent on the treatment of these other major asset categories.

\section{SUITABILITY OF DIFFERENT METHODS TO SPECIFIC APPLICATIONS}

Regulators and legislators have at least two major applications for transition cost estimation. The first is to identify and assess the extent of transition costs for utilities in their state or region. The second is to provide an analytical foundation for utility recovery of transition costs. Certain other applications, such as market simulations or market power assessments, may also be of interest to policymakers. Based on our earlier assessment of different approaches, which methods are suited to these applications?

\section{Problem Identification and Assessment}

For initial problem identification and assessment, ex ante administrative valuation approaches are the obvious choice. The primary question is whether to favor bottom-up or top-down approaches. For regulatory commissions and legislatures with limited staff resources, simple approaches are preferred over complex ones. This suggests that a top-down approach is most appropriate for most cases. Yet even within this general category of approaches, the relative analytical complexity of specific top-down methods differs substantially. The PG\&E method, for example, which relies on a production cost simulation to project future utility revenues, may be too involved for initial problem assessments. In contrast, the Baxter and Hirst method (1995) is quite simple and yields general results that correspond closely to those generated by more complex formulations such as RDI; both methods identify a similar list of states where utilities may face substantial transition cost problems. Simple methods are also more amenable to quickly examining several different cases. The appropriate approach for this application captures the primary determinants of transition costs without undue complexity. Work to date strongly suggests that simple top-down, ex ante, administrative valuation methods will suffice for this purpose. 


\section{Regulatory Authorization for Utility Recovery of Transition Costs}

Proceedings to determine transition cost recovery will be important due to the potential costs involved for utilities and ratepayers. Ex ante approaches have much appeal because they provide an estimate of transition costs before restructuring is fully implemented. Administrative methods have the advantage of addressing all major categories of assets and liabilities, which is an important consideration for utilities with transition costs from more than one major category. In addition, administrative methods are especially appropriate where continued utility ownership of existing generation and transmission is not expected to impede operation of a competitive power market.

An important problem with ex ante administrative approaches is their reliance on forecasts of market prices and utility revenues. One approach to reduce the risks from forecast errors is to periodically reconcile forecasted and observed events and then adjust future cost recovery by the outcome of this reconciliation. A reconciliation process must focus on two major elements of the transition cost forecast: market price and expected utility revenue.

Important questions arise about developing appropriate indices for electricity market prices, especially in the short term. Spot market or wholesale market prices are available, but are these appropriate indicators for marginal generation cost? The Wall Street Journal, for example, publishes a daily spot price for electricity at the California-Oregon border. The New York Mercantile Exchange is working to establish a futures market for electricity, which will provide price information that could be used in valuation approaches. Power pools also provide price signals. Even here, the use of the pool price, which changes frequently, may not be straightforward. In its proposal to use the New England Power Pool system price as the market price for power, Boston Edison (1995) recommends three adjustments to the pool price: first, to reflect the marginal cost of the most expensive units running; second, to reflect the start-up costs for the last unit on line for dispatch; and third, to include shortage costs, which are the costs needed to induce customers to shed load during periods of capacity shortage. These adjustments are not insoluble technical difficulties but are an indication that use of a pool price is not as simple as some advocates of that approach have suggested. The problem is that we lack a mature market for long-run electricity generation. As a result, appropriate market price indicators are difficult to develop in the short term. The development effort is clearly worthwhile, however, to capture the benefits of the ex ante administrative approach.

Forecasting the utility revenues necessary to recover transition costs is the other major forecasting element subject to reconciliation. Its importance stems less from the difficulty of forecasting future costs than from a probable regulatory desire to encourage utilities to actively reduce transition costs by implementing productive efficiency measures and pursuing surplus power markets. Utilities assured of full recovery of embedded costs for the economic lives of the affected assets lack incentives to reduce transition costs. Options to build into a utility revenue forecast include the implementation of performance-based rate making or the establishment of a defined transition period with gradually decreasing transition cost recovery over time. The reconciliation process then compares the utility's actual performance to the performance targets. A key element of this approach is to ensure that customers receive the proper price signals from electricity suppliers. Following the example from Chapter 2, one way to send the appropriate 
price signals is to unbundle customers' electricity bills into at least two components: marginal generation costs and all other system costs. This would help customers make economic choices among alternate suppliers and reduce the likelihood of creating additional transition costs from uneconomic bypass of utility systems.

Because no research has been done on the comparative accuracy of bottom-up versus top-down approaches, the choice of one or the other approach is a judgement call at this time. ${ }^{12}$ The present trade-off is between the administrative ease of the top-down approaches and the detail and analytical rigor of the bottom-up methods.

The MPUC proposal represents an alternative to reconciliation worth considering. The MPUC approach accepts a certain level of forecast error as inevitable. Transition costs estimates are revisited only if an interested party demonstrates that actual transition costs have exceeded the previous estimates by a predetermined amount. Establishing this threshold in advance will be contentious, but the task will be easier if parties are convinced that the initial transition cost estimates are not intentionally biased and, as in the Maine proposal, the utilities receive incentives to mitigate transition costs.

Another option is to use different valuation approaches for different asset categories-market valuation for generation and administrative valuation for other assets, for example. This option is desirable where market power is an issue. Here a properly structured auction or sale accomplishes two objectives: providing a clear indicator of market value and distributing existing generation assets among several competitors. Without market power concerns as a motivator, however, regulators may find implementing more than one valuation approach to be unnecessarily complex.

\section{Other Applications}

In addition to the two major applications just discussed, transition cost estimation approaches have other applications. Examples include market simulations, market power assessments, and asset profitability analysis. Policymakers have concerns with all three areas and will thus benefit from the insights appropriate analysis provides. Our assessment suggests that market simulation and market power analyses are best served by the type of bottom-up administrative valuation approaches we reviewed. These applications simulate individual asset performance in response to changing market conditions. Bottom-up approaches are particularly well suited to forecasting asset performance in a competitive market. Thus, a market power assessment might examine the effects of different configurations of existing asset portfolios on wholesale market operations. Among the issues that could be addressed are the effects of additional suppliers with smaller asset portfolios on wholesale market performance. Asset profitability analysis is perhaps also best served by a bottom-up approach, but top-down methods that include production cost analysis, such as PG\&E's, may be used to assess the performance of individual generating assets in the face of static market price assumptions.

\footnotetext{
${ }^{12}$ The next phase of Oak Ridge National Laboratory research on transition costs is addressing this question.
} 


\section{CONCLUSIONS AND RECOMMENDATIONS}

\section{REGULATION AND TRANSITION COSTS}

Asset values are assessed differently in regulated and competitive environments. In a regulated environment, an asset's book value - the original cost minus any accumulated depreciation-defines it value. For the utility's asset portfolio, regulators set rates to ensure a revenue flow that recovers the portfolio's costs, including depreciation, operating costs, and an ROI. In a competitive environment, asset value is determined by the net income flows attributable to the asset. These flows, over time, are a function of the asset's costs and the price obtained for the asset's services. The market sets this price in a competitive environment. Any industry with undepreciated assets that moves from a regulated market to a competitive market may not be able to recover undepreciated sunk costs at prevailing market prices.

Transition costs are important for two reasons as regulators move to deregulate electricity generation. First, generation costs dominate the industry's total costs, and a number of utilities have embedded generation costs that exceed power prices on the wholesale market or even the expected cost of new supply. As a result, the deregulation of generation affects the most important portion of the regulated industry's costs. In addition, certain utilities with embedded costs that cannot be recovered at competitive market prices face serious financial difficulties should deregulation proceed too quickly. The customers of these same utilities face equivalent reductions in consumer welfare should deregulation occur too slowly.

Second, utilities provide multiple services to customers, yet customers face a bundled rate. The resulting temptation.is great to compare utilities' bundled prices, which reflect generation, transmission, distribution, and related ancillary services, to the generation-only prices of alternate suppliers. The comparison of the utility's bundled rate to a competitor's wholesale or generation-only price will lead customers to make some choices that are inefficient from society's perspective. Once deregulation is underway, regulators can reduce the probability of uneconomic bypass of existing suppliers by unbundling rates into at least marginal generation costs and remaining system costs, thereby reducing transition costs. Utilities can mitigate transition costs by reducing their total costs and by pursuing markets where they offer competitive services.

Regulators must carefully assess the consequences of different deregulation proposals on transition costs. In jurisdictions with serious transition cost problems, a quick move to deregulate generation combined with no action on transition cost recovery will result in substantial financial losses for utilities and shareholders. Regulators that authorize some recovery of transition costs and are committed to avoiding cost shifts among different customer classes should not expect substantial and immediate decreases in electricity prices. 


\section{ITEMS INCLUDED IN TRANSITION COSTS}

Four major categories of costs are candidates for inclusion in transition costs estimates: utilityowned generation, long-term contractual obligations for fuel and power, regulatory assets, and public policy programs. Regulators and many analysts appear to be reaching agreement that certain costs arising from utility-owned generation and all costs from long-term contractual obligations are appropriately included as transition costs. For utility-owned generation, many observers believe that utilities should be allowed to recover the net generating plant in service that is below market value. Most also agree that the appropriate way to quantify net plant in service is by considering the net change in asset value of a utility's entire generating portfolio. Substantial disagreement remains about what other generation-related costs should be included as transition costs, though many argue that past costs are more appropriately included than future costs, such as plant additions.

There is widespread agreement that the above-market costs of long-term obligations for firm purchases, primarily power-purchase and fuel-supply contracts, must also be included as transition costs. The arguments are particularly strong in the case of above-market contracts for the long-term purchase of power from QFs. QFs developed in response to PURPA, and many utilities argue that they were compelled to enter these long-term obligations at the behest of regulators implementing these federal policies. In cases where utilities voluntarily entered power-purchase or fuel-supply contracts, observers are less likely to agree that any above-market costs should be included as transition costs.

Regulatory assets result from regulatory actions that permit utilities to allow future recovery of certain costs. These assets require continued regulation of a retail monopoly franchise to retain their value. In a purely competitive environment, regulatory assets have no market value. Because the potential costs are large, regulatory assets have assumed an increasingly important role in the debate on transition costs. The estimation issues center on determining which regulatory assets to include as transition costs and then determining the appropriate account balances for these assets. Consistent with the agreements being reached on utility-owned generation and long-run obligations, some observers suggest that only generation-related assets be included as transition costs.

Due to their monopoly status and role in the economy, electric utilities have been vested with several public-policy obligations by regulators and legislators. Utilities incur the costs of publicpolicy obligations due to specific regulatory or legislative actions. The utility costs of these obligations could be discontinued at any time by regulators or legislators. As a result, utility costs of public-policy obligations should not be treated as transition costs.

\section{ASSESSING APPROACHES TO ESTIMATING TRANSITION COSTS}

We identified eight general valuation options. These general options are defined using three categories, each with two elements: administrative versus market valuation; ex ante versus ex 
post valuation; and bottom-up versus top-down valuation. Each option has clear strengths. Administrative valuation options include all relevant categories of assets and liabilities. Market valuation approaches that use asset sales provide a clear indicator of value at the time of the sale. Ex ante approaches provide an early estimate of transition costs, thereby enabling suppliers and consumers to plan for an industry transition with these costs clearly established. Ex post methods resolve the uncertainties of anticipating the market response to industry restructuring by delaying valuation until restructuring is underway and a mature electricity market develops. Bottom-up options assign market values to individual assets. Top-down approaches are generally easier to understand and implement.

Unfortunately, each of the eight general options also has at least one important weakness. Ex ante administrative approaches rely on a forecast of market price, which creates potentially large risks for shareholders and ratepayers. Market valuation is not an effective approach when certain assets, such as regulatory assets, have no market value or when concerns with future liability or transfer of ownership discourage market interest, as with nuclear plants. Delaying valuation to the extent required for pure ex post approaches is unreasonable given the pressures utilities will face from financial markets to write off or mark down certain assets well before a mature electricity market develops. Bottom-up approaches are data intensive and computationally complex, both of which will contribute to implementation difficulties in any public proceeding to authorize utility recovery of transition costs. Top-down approaches do not assign changes in value to specific assets, as utility accounting practices may require. As a result of each general approach's weaknesses, combinations of the general approaches are needed or solutions must be developed to address the weaknesses of a selected approach.

We recommend regulators consider the following when assessing specific estimation approaches.

- Understand clearly the implementation requirements of each approach, both administrative and technical.

- Assess the relative administrative ease of implementing each approach. For the approaches we reviewed, relative administrative ease decreases as the detail and sophistication of the proposed estimation approach increases.

- Base transition cost estimates used to support utility cost recovery on publicly-available data and models.

- Ensure that the estimation approach includes all relevant assets and liabilities that regulators determine are contributing to transition costs.

- Determine the relevant time-period to include in transition cost estimates.

- Carefully assess how the estimation approach estimates market price.

- Ensure that regulated and competitive market prices are constructed comparably. The comparison of regulated market price to competitive market price, which is the characteristic feature of administrative valuation approaches, will provide appropriate results only if the two prices are composed of comparable cost categories. Be aware of the effects of income taxes on transition costs-under administrative valuation approaches, shareholder losses will be net of income taxes. 
- Consider the effects of market dynamics over time on transition cost estimates.

We identified 15 specific estimation approaches and applied the above eight criteria to seven of those approaches. Based on our assessment, we recommend that regulators use ex ante administrative valuation approaches to initially assess the potential existence and extent of transition cost problems in their jurisdictions. Top-down methods will be most suitable for organizations with limited resources or when the detail provided by a bottom-up approach is unnecessary.

When the application is for regulatory authorization of transition cost recovery, we recommend the use of ex ante administrative valuation approaches where continued utility ownership of existing generation and transmission assets is not a major concern. At least two options are available to address the forecast risk introduced by ex ante administrative approaches.

- First, regulators can implement a reconciliation process to periodically compare forecasted to observed events and then appropriately adjust subsequent transition cost recovery. Reconciliation must focus on the market price and utility revenue elements of the transition cost forecast. Implementing a reconciliation process requires the development of appropriate market price indicators. Other important parts of an administrative valuation approach are the use of incentives for utilities to mitigate transition costs and the unbundling of utility rates to insure that consumers receive proper electricity price signals.

- Alternatively, regulators could recognize that a certain level of forecast error is unavoidable. Reconciliation would then only be initiated if an interested party demonstrates that actual transition costs deviate from the forecast by a predetermined amount.

Market valuation is an attractive approach when continued utility dominance of generation markets is a substantial concern. The sale of less marketable generation assets will be enhanced by combining these less attractive assets with more attractive assets. The Sant and Naill proposal combines this feature with a long-term power purchase contract between the asset buyers and sellers. If retail competition is an objective, however, this proposal delays retail competition until the initial power-purchase agreement expires. Disposition of nuclear assets is also a key problem with market valuation approaches. In addition, regulators will still have to use administrative methods to value the contribution of other major asset categories to transition costs.

Transition cost issues continue to impede efforts to deregulate electricity generation. This report is the second from a larger DOE-sponsored project on transition costs in the electric-utility industry. Future efforts will focus on comparing the relative accuracy of bottom-up and topdown estimation approaches, illustrating how to implement several of the specific approaches discussed in this report using an integrated utility financial and generation dispatch model, and examining the effects of different mitigation strategies on transition costs. 


\section{ACKNOWLEDGEMENTS}

We thank Val Jensen for his continuing support of this project. We thank Stan Hadley and Eric Hirst for their insights on utility finances and future market structures and Ken Rose for sharing his ideas on the economics of transition costs. We thank Tom Austin, Bob Harrold, Joe Jenkins, Dan Johnson, Steve Linsey, Ron Matlock, Warren Myers, Mark Reeder, John Rohrbach, Margaret Vanhaften, and Richard Zuraski for discussing state activities on transition cost issues. Thanks also to Wayne Coste, Tom Feiler, Paul Fremont, and Robijn Hornstra for their efforts to assist us in accurately characterizing their estimation methods. We thank Steve Anderson, David Boomsma, Wayne Coste, Paul Fremont, Don Hall, Stan Hadley, Eric Hirst, Robijn Hornstra, Val Jensen, Roger Naill, Kevin Porter, Ken Rose, and Michael Yokell for their helpful comments on a draft of this report. Finally, thanks to Virgie Sapp for editorial support. 



\section{REFERENCES}

American Public Power Association 1994, Comments of American Public Power Association in FERC's NOPR on Recovery of Stranded Costs, submitted to the Federal Energy Regulatory Commission in Docket RM94-7-000, Washington, D. C., December 9.

Anderson, S., J. Graham, and W. Hogan 1993, "Electricity Transition Costs," draft paper prepared for the Harvard Electricity Policy Group, Harvard University, Cambridge, October 22.

Andersson, R. and M. Bohman 1985, "Short- and Long-Run Marginal Cost Pricing: On Their Alleged Equivalence," Energy Economics 7:279-88.

Barkovich, B. 1994, Testimony of Dr. Barbara R. Barkovich on Behalf of the California Large Energy Consumers Association, California Manufacturers Association, California State Department of General Services and Industrial Users, submitted to the California Public Utilities Commission in Docket No. R.94-04-031, San Francisco, December 5.

Baxter, L. and E. Hirst 1995, Estimating Potential Stranded Commitments for U.S. InvestorOwned Electric Utilities, ORNL/CON-406, Oak Ridge National Laboratory, Oak Ridge, TN.

Bonbright, J., A. Danielsen, and D. Kamerschen 1988, Principles of Public Utility Rates, 2nd ed., Public Utility Reports, Inc., Arlington, VA.

Boston Edison 1995, Comments of Boston Edison Company Concerning the Restructuring of the Electric Utility Industry in Massachusetts, submitted to the Massachusetts Department of Public Utilities in Docket No. D.P.U. 95-30, Boston, March 31.

CEC (California Energy Commission) 1994, Testimony of the California Energy Commission on Uneconomic Assets and Obligations, submitted to the California Public Utilities Commission in Docket No. R.94-04-031, Sacramento, CA, December 5.

Code of Federal Regulations 1994, Conservation of Power and Water Resources, 18, Part 101, Office of the Federal Register, National Archives and Records Administration, Washington, D.C., April 1.

Copeland, T. and J. Murrin 1990, Valuation: Measuring and Managing the Value of Companies, John Wiley \& Sons, New York.

Coste, W. and G. Adams 1994, Electric Market Price Forecasts, Resource Data International, Inc., Boulder $\mathrm{CO}$. 
Costello, K. 1994, "The Natural Gas Experience," in Hempling, Rose, and Burns (1994), pp. 99-102.

CPUC (California Public Utilities Commission) 1994a, Assigned Commissioner's Ruling, Docket No. R.94-04-031, San Francisco, October 27.

CPUC 1994b, Order Instituting Rulemaking and Order Instituting Investigation on the Commission's Proposed Policies Governing Restructuring California's Electric Services Industry and Reforming Regulation, Docket Nos. R.94-04-031 and I.94-04-032, San Francisco, April 24.

CPUC 1995, Proposed Policy Decision Adopting a Preferred Industry Structure, Docket No. R.94-04-031, San Francisco, May 24.

EEI (Edison Electric Institute)1994, Initial Comments of Edison Electric Institute, submitted to the Federal Energy Regulatory Commission in Docket RM94-7-000, Washington, D. C., December 9.

ELCON (Electricity Consumers Resource Council), AISI (American Iron and Steel Institute), and CMA (Chemical Manufacturers Association) 1994, Comments of the Electricity Consumers Resource Council, the American Iron and Steel Institute, and the Chemical Manufacturers Association, submitted to the Federal Energy Regulatory Commission in Docket RM94-7-000, Washington, D. C., December 9.

Energy Information Administration 1995, Financial Statistics of Major U.S. Investor-Owned Electric Utilities 1993, DOE/EIA-0437(93)/1, U.S. Department of Energy, Washington, D.C.

Feiler, T. and C. Seiple 1995, "Electric Stranded Investment: Not as Much as You Think," Public Utilities Fortnightly 133(2):10-11.

FERC (Federal Energy Regulatory Commission) 1994, Notice of Proposed Rulemaking: Recovery of Stranded Costs by Public Utilities and Transmitting Utilities, Docket No. RM94-7000, Washington, D.C., June 29.

FERC 1995, Notice of Proposed Rulemaking and Supplemental Notice of Proposed Rulemaking: Promoting Wholesale Competition Through Open Access Non-discriminatory Transmission Services by Public Utilities; Recovery of Stranded Costs by Public Utilities and Transmitting Utilities, Docket Nos. RM95-8-000 and RM94-7-001, Washington, D.C., March 29.

Financial Accounting Standards Board 1982, Statement of Financial Accounting Standards No. 71: Accounting for the Effects of Certain Types of Regulation, Financial Accounting Standards Board, Stamford, CT. 
Flaim, T. 1994, "Methods for Dealing with Transition Costs for the Electric Utility Industry," in The Electric Industry in Transition, Public Utilities Reports, Inc. and New York State Energy Research and Development Authority, Arlington, VA, pp. 171-84.

Graniere, R. 1994, "The Telecommunications Experience," in Hempling, Rose, and Burns (1994), pp. 103-105.

Hempling, S., K. Rose, and R. Burns 1994, The Regulatory Treatment of Embedded Costs Exceeding Market Prices: Transition to a Competitive Electric Generation Market, The National Regulatory Research Institute, Columbus, $\mathrm{OH}$, November 7.

Hogan, W. 1994, "Stranded Assets and Options for the Transition: Legal Transitions, Compensation, and the Cost of Shifting Costs," presentation for the Harvard Electricity Policy Group, Harvard University, Cambridge, January 14.

IEP (Independent Energy Producers Association) 1994, Comments of the Independent Energy Producers Association, submitted to the California Public Utilities Commission in Docket No. R.94-04-031, Sacramento, CA, June 8.

Kahn, A. 1970, The Economics of Regulation Volume I: Principles, John Wiley, New York.

Kahn, E. 1994, "Preparing for the Inevitable: The Nationalization of the U.S. Nuclear Industry in a Competitive Electricity Market," in The Electric Industry in Transition, Public Utilities Reports, Inc. and New York State Energy Research and Development Authority, Arlington, VA, pp. 199-214.

Kirby, B., E. Hirst, and J. Vancoevering 1995, Identification and Definition of Unbundled Electric Generation and Transmission Services, ORNL/CON-415, Oak Ridge National Laboratory, Oak Ridge, TN.

Michaels, R. 1994, "Unused and Useless: The Strange Economics of Stranded Investment," The Electricity Journal 7:12-22.

Moody's Investors Service 1994a, "U.S. Electric Utilities: Break-Even Analysis Reveals Large Variation in Generating Costs," Moody's Investor Service, New York, June.

Moody's Investors Service 1994b, "California Break-Even Analysis," Moody's Investor Service, New York, December.

Moody's Investors Service 1995, "Stranded Costs Will Threaten Credit Quality of U.S. Electrics," Moody's Investor Service, New York, August.

MPUC (Maine Public Utilities Commission) 1995, Recovery of Stranded Cost Rulemaking (Chapter 392), Docket No. 95-055, Maine Public Utilities Commission, Augusta, February 27. 
NERC (North American Electric Reliability Council) 1995, ES\&D, NERC's Electricity Supply \& Demand Database and Software, Version 2.0, Princeton, NJ.

NYPSC (New York Public Service Commission) 1994, Order Re: Sithe/Independent Power Partners, L.P., Case 94-E-0136, Albany, November 3.

PG\&E (Pacific Gas \& Electric Company) 1994a, Competition Transition Charge Testimony, submitted to the California Public Utilities Commission in Docket No. R.94-04-031, San Francisco, November 18.

PG\&E 1994b, Workpapers: Competition Transition Charge Testimony, submitted to the California Public Utilities Commission in Docket No. R.94-04-031, San Francisco, November 18.

RDI (Resource Data International, Inc.) 1994a, Retail Power Markets in the U.S.: Executive Summary Excerpt, Resource Data International, Inc., Boulder, CO.

RDI 1994b, "Appendix A-The Inter-Regional Electric Market Model," in Retail Power Markets in the U.S., Resource Data International, Inc., Boulder, CO, pp. 1-17.

R. J. Rudden Associates, Inc. 1994, "Quantifying Competitive Forces in the Electric Industry," The Rudden Resource, Vol. 7, Hauppauge, NY.

Rose, K. 1995a, "The Economics of Electric Utility Transition Costs," draft paper presented to the NARUC Committee on Electricity, Washington, D. C., February 27.

Rose, K. 1995b, "Electric Utility Industry Restructuring and Transition Costs: Reconciling Economic Efficiency and Regulatory Consistency," White Paper \#4, The Joint NARUC/EEI Seminar on Regulating in a Transitional Environment, Providence, RI, April 13.

Sant, R. and R. Naill 1994, "Let's Make Electricity Generation Competitive," The Electricity Journal 7:49-57.

SCE (Southern California Edison) 1994, Testimony on the Competition Transition Charge, submitted to the California Public Utilities Commission in Docket No. R.94-04-031, Rosemead, CA, November 18.

SDG\&E (San Diego Gas \& Electric Company) 1994a, Comments of San Diego Gas \& Electric Company on Proposed Policies Governing Restructuring Electric Services Industry and Reforming Regulation, submitted to the California Public Utilities Commission in Docket No. R.94-04-031, San Diego, June 8. 
SDG\&E 1994b, Prepared Testimony of San Diego Gas \& Electric Company on Transition Costs, submitted to the California Public Utilities Commission in Docket No. R.94-04-031, San Diego, November 18.

Shepherd, W. 1985, Public Policies Toward Business, Richard Irwin, Inc., Homewood, IL.

Tonn, B., E. Hirst, and D. Bauer 1995, Public-Policy Responsibilities in a Restructured Electricity Industry, ORNL/CON-420, Oak Ridge National Laboratory, Oak Ridge, TN.

Utility Working Group 1994, Comments of the Utility Working Group, submitted to the Federal Energy Regulatory Commission in Docket RM94-7-000, Washington, D. C., December 9.

Weston, F. and E. Brigham 1978, Managerial Finance, 6th ed., Dryden Press, Hinsdale, IL.

Yokell, M., D. Doyle, and R. Koppe 1995, "Stranded Nuclear Assets and What To Do About Them," presented at the DOE/NARUC Electricity Forum, Providence, RI, April 21. 


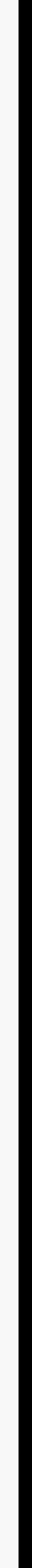




\section{CATEGORIES USED TO DESCRIBE DIFFERENT ESTIMATION APPROACHES}

We used the following categories to describe the different transition cost estimation approaches reviewed for this study. The approaches assessed in detail in Chapter 6 are described in Appendix B using these categories.

\section{TYPE OF METHOD (CLASSIFICATION FRAMEWORK)}

The type of method describes the basic approach to estimating transition costs. Administrative valuation approaches use analytical methods to assess asset values relative to an estimate or forecast of market price. Market valuation approaches rely on sale or divestiture of assets to determine their market values. We discussed this basic classification framework, which was suggested initially by SDG\&E (1994a), in an earlier report (Baxter and Hirst 1995). The framework identifies eight general options to estimate transition costs.

\section{Administrative Valuation, Ex Ante, Bottom Up}

This is an asset-by-asset valuation using forecasts of market price (either endogenous or exogenous) and each asset's total production and capital costs, or in the case of contracts, the contract terms and conditions. The method usually compares operating revenues to fixed costs with any shortfall in fixed-cost recovery equaling the transition costs. All assets require a market price comparison except for regulatory assets.

\section{Administrative Valuation, Ex Ante, Top Down}

This approach values assets and liabilities as a portfolio or by major category using forecasts of market price (either endogenous or exogenous) and retail rates. The method usually compares expected revenues in the absence of deregulation to expected revenues under deregulation. It captures all assets and liabilities included in rates. Regulatory assets require separate treatment.

\section{Administrative Valuation, Ex Post, Bottom Up}

Ex post, bottom-up, administrative valuation differs from the ex ante approach by using observed market prices, retail rates, and energy generated by the utility or delivered by long-term contract rather than forecasts. The method captures all assets and liabilities included in rates or contracts. Again, regulatory assets require separate treatment. 


\section{Administrative Valuation, Ex Post, Top Down}

This is a valuation of assets and liabilities as a whole or by major category using observed market prices, retail rates, and energy generated by the utility or delivered by long-term contract. The method captures all assets and liabilities included in rates or contracts. Regulatory assets require separate treatment.

\section{Market Valuation, Ex Ante, Bottom Up}

In this method, the value of individual assets is determined through a sale or auction. The purchase price determines the market value and the difference between book and market value determines the transition costs. These costs could be positive (book in excess of market) or negative (market in excess of book). The sale or auction may be conducted by the utility, by the state, or by a third party. Ex ante indicates that the sale or auction takes place before the full details of a restructured industry are adopted or in place.

\section{Market Valuation, Ex Ante, Top Down}

This method is the same as the ex ante bottom-up approach, except that packages of assets are assembled for sale or auction. In addition, packages of assets may be spun off from the existing utility to new independent generating companies. In this case, the stock value and number of outstanding shares determine the market value of the asset packages.

\section{Market Valuation, Ex Post, Bottom Up}

This method is the same as market valuation, ex ante, bottom up, but the sale or auction takes place after restructuring is complete and a mature generation market develops.

\section{Market Valuation, Ex Post, Top Down}

The same method as market valuation, ex ante, top down, but the sale or auction takes place after the competitive generation market matures.

\section{IMPLEMENTATION}

Implementation describes how valuation is conducted technically and procedurally. Administrative valuation methods typically are implemented by computer spreadsheet or computer model(s). Market valuation methods are implemented by auction, sale, spin-off, or some other market process. Implementation also refers to the need for regulatory proceedings to review estimates, estimation methods, or supporting data. 


\section{PUBLICLY AVAILABLE DATA OR MODELS}

This category indicates whether the data or models necessary to calculate transition costs are publicly available or proprietary. A proprietary model may be available through licensing agreements or other commercial arrangements.

\section{LEVEL OF AGGREGATION}

This refers primarily to how assets are grouped for valuation. In bottom-up approaches, individual assets are typically the unit of analysis. In top-down approaches, the entire utility portfolio, or major portions of the portfolio, is the unit of analysis.

\section{CATEGORIES INCLUDED}

This refers to the categories of assets or liabilities included in the analysis. These may include utility generation, long-term power purchase or fuel-supply contracts, regulatory assets, public policy programs, and other assets.

\section{COSTS INCLUDED}

This describes the costs included in each category. For example, utility generation may include fixed costs, variable costs, and an ROI. Power-purchase contracts may include energy payments, capacity payments, and other costs. Regulatory assets may include all assets or generationrelated assets.

\section{MARKET PRICE (VALUE) DETERMINATION}

The market price determination describes the methods and assumptions used to determine market prices or values. These methods may range from a single-year estimate (derived from utility "requests for power" or bid data for new power), which may then be escalated, to a multiyear forecast based on market simulations of buyers and sellers in a competitive environment. The single-year estimate may be divided into price components and each component escalated at different rates. The market price may also be based on an assumption. For a market determination, such as an auction, the market value is determined by buyers' willingness to pay for assets at the time the auction is held.

Particularly for administrative determinations that rely on analytical methods, the composition of the market price must be comparable with the retail price. For example, if the retail price contains variable costs, or transmission and distribution costs, then the market price must also include these costs to insure appropriate estimation of transition costs. 


\section{RETAIL PRICE (VALUE) DETERMINATION}

Retail price determination describes the methods and assumptions used to estimate retail (regulated) price or the price utility customers would face if wholesale or retail markets were not competitive and the utility franchise remained intact. It may also include the methods or assumptions used to determine the utility sales at risk from competition (the timing and nature of any restructuring will determine the sales at risk). For administrative methods, the retail price may be estimated for the entire portfolio of utility assets, for categories of assets, or for individual assets. The retail price should be as close as possible to a "generation-only" price (or care must be taken to match the components of the market price). Prices and sales may be taken from a single year (and then projected for a given duration) or forecasted for several years. Utility generation is often forecast using production simulation models. Revenue requirement models then estimate the dollars the utility must collect from customers to cover all costs (or revenue requirement may be determined over time in regulatory proceedings; future revenue requirements may be based on some type of incentive or performance-based rate rather than a cost-based rate). QF generation is based on contracted delivery amounts. QF prices are determined by the terms and conditions of contracts. For market simulation approaches, retail price is determined by the marginal production costs of individual plants. Revenue from individual plants depend on market prices and physical constraints (such as transmission).

For auction approaches, retail value may be the book value of the asset or determined by conditions or terms included in the purchase contract.

\section{TIME PERIOD}

This refers to the time period incorporated in the transition cost estimate. The time period differs depending on the level of aggregation in the analysis. For example, the time periods covered for utility generation and $\mathrm{QF}$ contracts often differ because the remaining lifetimes of undepreciated utility assets and contracts differ. The time period for an auction or sale refers to the duration of the sale process or the time elapsed between restructuring and the auction. 


\section{OVERVIEWS OF SPECIFIC ESTIMATION APPROACHES}

\section{CALIFORNIA PUBLIC UTUITIES COMMISSION (1995)}

\section{Type of Method}

The CPUC proposal does not provide the details of a specific method. Many implementation issues remain open and will be the subject of upcoming hearings. The CPUC proposal instead presents the outlines of an approach to transition cost estimation, and it is these outlines that are described here.

Two approaches are discussed. The first approach is used when generation assets continue to be owned by the utility. Under this approach, the CPUC will use an administrative, ex ante method with a periodic reconciliation process. The CPUC has not decided on a top-down or bottom-up method. The second approach is used when the utility divests generation assets, either through a sale or spin-off to an affiliate. Under this approach, the CPUC will use ex post market valuation.

Because the CPUC proposal does not require divestiture, the CPUC assumes that some type of administrative determination of transition costs must be made. The agency anticipates that it will use a periodic transition cost administrative proceeding to reconcile a prior forecast with observed events for that period.

\section{Implementation}

The CPUC has not determined how transition cost estimation will be implemented. The administrative approach will involve a proceeding to estimate initial transition costs and then subsequent proceedings to reconcile the forecasts with observed conditions. The market valuation approach may also involve a proceeding to determine the most appropriate indicator of market value in the event of a spin-off.

The CPUC is addressing transition cost estimation issues in its utility industry restructuring rulemaking. A basic understanding of the CPUC's majority proposal helps clarify the agency's approach to transition costs. The core of the CPUC's restructuring proposal is the creation of a transparent wholesale pool under the control and operation of an independent system operator. All transmission assets are controlled by the independent system operator. The operator's primary responsibilities are to ensure open transmission access, to conduct auctions to determine the economically efficient price for generation, and to perform economic dispatch of generation. 
Pool participants, including the state's three investor-owned utilities, must purchase all electricity from the pool.

\section{Publicly Available Data/Models}

An administrative approach will probably involve a public proceeding to review data, methods (at least initially), and results.

\section{Level of Aggregation}

Generation assets, utility contracts with QFs, and regulatory assets will be estimated separately. In addition, nuclear and hydro power plants will be treated distinctly from other generation assets.

\section{Categories Included}

The CPUC defines uneconomic asset costs as the difference between the book value associated with generation assets and the market value of that generation. Market value is defined as the net present value of the stream of revenue resulting from electricity sales from the asset(s). The proposal combines nuclear and hydro power plants for each utility in hope that the average electricity price from these two resource types is competitive with pool prices. In addition, these resources will not face competition in the pool. The pool operator will dispatch nuclear and hydro resources either as they are available or according to settlement terms the CPUC agreed to in prior proceedings. The intent here is to reduce or eliminate the need to recover explicit transition costs from these resources (as well as recognizing that certain of these resources may be difficult to sell). The pool would continue to take power from these resources in this manner until all associated transition costs were recovered. In cases where the combination of nuclear and hydro resources was insufficient to avoid transition costs, any revenue shortfalls would be classified as transition costs. Once all transition costs associated with nuclear power plants are recovered, the utility will reserve the use of hydro resources for its customers.

For any nonnuclear and nonhydro assets under utility ownership, the proposal sets a limit on the utility's authorized rate of return ( \pm 150 basis points). The utility would not recover transition costs unless the rate of return for these assets fell more than 150 basis points below its authorized rate of return. A rate of return more than 150 basis points above its authorized rate will result in a credit toward reducing transition costs.

For utility contracts with $\mathrm{QF}$ facilities, utilities will continue purchasing power according to existing contracts. Costs above market will be collected as transition costs. Utilities will be allowed to retain $20 \%$ of any renegotiations of capacity payments to QFs. The pool operator must continue to honor utility commitments to purchase $\mathrm{QF}$ power.

The CPUC will allow full recovery of all regulatory assets related to generation. The CPUC has not determined the specific regulatory asset accounts related to generation. 


\section{Costs Included}

For utility-owned generation, recovery will include fixed costs. Recovery of QF contract costs will include energy payments, capacity payments, and other costs. Regulatory assets will include all generation-related assets.

\section{Market Price (Value) Determination}

For administrative valuation, the pool price will equal the market price. It is not clear whether the method will ultimately use the hourly pool price or an average of hourly prices over the year. For market valuation, the results of a sale or auction will determine the market value directly. Should the utility spin off assets, the market value will be the product of the stock price of the affiliate and the number of shares. What remains to be determined is when precisely to make these observations subsequent to the spin-off. Should the utility decide to shut down a plant, the utility will recover the book value of the plant net of its estimated salvage value.

\section{Retail Price (Value) Determination}

The book value of utility generation or the full contract value of $\mathrm{QF}$ payments will equal the retail price.

\section{Time Period}

The time period is the number of years needed to fully collect all transition costs. QF transition costs accrue yearly, for example, and run the life of the existing contracts unless these contracts are renegotiated.

\section{FEDERAL ENERGY REGULATORY COMMISSION (1995)}

\section{Type of Method}

The FERC approach is administrative, top down (wholesale stranded costs only). An outstanding issue is whether the method will be applied ex ante or ex post. FERC proposes to subtract the competitive market value of the power the customer would have purchased from the utility (and the basic revenues from the transmission service) had the customer continued to take service under its contract from the revenues that the customer would have paid the utility. The fundamental approach is to estimate the difference between a wholesale rate and a wholesale market price and then multiply this difference by the lost sales to the utility.

\section{Implementation}

The utility implements transition cost estimation at the customer's request. Disputes between utilities and departing customers will be resolved by FERC. FERC's approach is focused on 
wholesale customers that become transmission-only customers and that have existing wholesale contracts (executed before July 11, 1995) without notice provisions.

\section{Publicly Available Data/Models}

The utility provides the formula and result (transition costs without mitigation) to the customer.

\section{Level of Aggregation}

Transition costs are estimated for individual customers.

\section{Categories Included}

FERC argues that the lost revenues approach eliminates the need to enumerate specific categories of assets. However, FERC notes that there may be categories of costs that are properly allocated to departing customers that are not captured in the lost revenues approach, using as an example nuclear decommissioning costs. The issue of costs that warrant special consideration is outstanding.

By implication, the FERC approach includes all categories represented in the utility's wholesale rate. For the wholesale market, these categories will be almost exclusively generation-related. The most commonly represented categories will be utility generation, QF contracts, and other long-term power purchase contracts.

\section{Costs Included}

The costs included are the same as the categories included. To the extent that utility wholesale rates and market wholesale rates contain comparable categories of costs, the lost revenue approach will be based on an appropriate price comparison. If, however, the utility wholesale rate includes a transmission charge, the wholesale market price does not include such a charge, and FERC does not wish to attribute transition costs to transmission assets, then the two prices are not constructed from comparable categories and the resulting transition cost estimate will be biased.

\section{Market Price (Value) Determination}

Market price determination is not specified in the FERC approach and remains an outstanding issue.

\section{Retail Price (Value) Determination}

Again, this is not specified in the FERC approach and is an outstanding issue. 


\section{Time Period}

The time period is not specified and is an outstanding issue.

\section{MAINE PUBLIC UTHITIES COMMISSION (1995)}

\section{Type of Method}

The MPUC method is an administrative, ex ante, top-down approach. This draft proposal defines transition costs as the difference between the utility's embedded costs (retail rate) and its marginal costs for the services no longer provided to departing customers. Transition costs are administratively adjusted for a utility by a mitigation factor $(0.5)$. The mitigation factor is arbitrary and, because it is imposed immediately, provides a strong incentive (or burden) for utilities to immediately cut costs. Utilities file per unit estimates for each customer class over the projected transition period.

\section{Implementation}

The utility provides generic annual estimates of transition costs for different customer classes. These estimates will be reviewed and approved in a generic proceeding. Actual exit fees will be calculated, based on the generic estimate, for customers departing the utility system. The proposed rulemaking covers new electric utilities authorized to provide service in an existing utility's exclusive service territory (e.g., municipalization) and nonexclusive service territories where the utility currently providing service has a demonstrable expectation that service will continue (e.g. municipal utility, or other wholesale customer). The generic proceeding is intended to eliminate the need to individually litigate each departing customer's exit fee. The generic transition cost estimates must be revised if it is shown that they differ from existing estimates by $20 \%$ or more on a present value basis over the remainder of the transition period.

\section{Publicly Available Data/Models}

Utility generic estimates will be examined in a public proceeding.

\section{Level of Aggregation}

The customer rate class is the unit of analysis. Generic estimates are customized to customer class based on customer demand and average electricity use.

\section{Categories Included}

The categories included are not explicitly defined. Embedded cost includes all categories embodied in retail rates (utility-owned generation, transmission, distribution, long-term firm power purchases, regulatory assets). Marginal cost appears to be defined broadly and also 
potentially includes all categories. The MPUC indicates that marginal cost estimates are for services no longer provided to departing customers. Thus, if a utility continues to provide transmission service but not generation or distribution, then marginal cost will include these latter two categories.

\section{Costs Included}

Fixed costs and ROI for utility assets are included costs. To the extent that the marginal cost estimate includes long-term, firm power-purchase costs, then the transition cost estimate will include fixed costs and ROI for these contracts. If the marginal cost estimate includes just utility production, however, then all long-term, firm power-purchase costs will be included in the transition cost estimate (because the costs are included in embedded costs and excluded in marginal costs).

\section{Market Price (Value) Determination}

The proposed rule defines the utility's marginal cost of service as its market value. While not stated by the MPUC, this approach (transition cost based on the difference between embedded rates and utility marginal costs for services not provided to the departing customer) to market value determination has the benefit of sending price signals to customers that will discourage uneconomic bypass of the utility's system. Marginal costs are defined as long-term marginal costs and are to be determined according to applicable MPUC decisions while following the most recent MPUC precedent to the greatest degree possible.

Marginal costs are generally complex to calculate and are sensitive to assumptions about utility system operation and costs. If the MPUC has previously litigated the questions of appropriate methods and assumptions, however, this may reduce controversy with their use in this proceeding. Still, the methods used to estimate marginal costs are likely to appear as "black boxes" to those outside the utility.

\section{Retail Price (Value) Determination}

Embedded costs are defined as existing rates at the time of the generic proceedings. For smaller customer classes (customers less than $1 \mathrm{MW}$ ), transition costs will be based on the average rate per kWh. For larger customer classes (customers greater than $1 \mathrm{MW}$ ), transition costs will be based on the average rate for each rate element (e.g., energy and demand charges). The customer-specific exit fee will be based on the average use of the departing customer over the prior three years. For smaller customers, this estimate will be based on the customer class average. For larger customers, this estimate will be based on each customer's use. The exit fee will be reduced to account for any services the departing customer continues to take from its current retail utility.

This approach ignores changes in utility rates during the transition period unless these changes alter the generic transition cost estimate by at least $20 \%$. 


\section{Time Period}

The time period will be the earlier of ten years or the time at which projections indicate a convergence of utility embedded and marginal costs.

\section{MOODY'S INVESTOR SERVICE (1994a, b, 1995)}

\section{Type of Method}

Moody's uses an administrative valuation, ex ante, top-down approach. A unique feature of Moody's approach is the method for estimating market prices. Moody's approach assumes that in a competitive generation market suppliers will charge for energy and capacity. Moody's estimates market prices for each of these services.

\section{Implementation}

Transition costs are estimated by spreadsheet. Transition costs for a single year are estimated as the difference between a utility's break-even price for capacity $(\$ / \mathrm{kW})$, adjusted for purchased power and regulatory assets, and a region's market price for capacity $(\$ / \mathrm{kW})$ multiplied by the utility's total capacity, including capacity available from power purchases. The total transition cost estimate for each utility is the present value of this annual loss over ten years at a $9 \%$ discount rate.

\section{Publicly Available Data/Models}

Primary data on utility costs and demand are from FERC Form 1. Supply and demand projections by region are from NERC. Regulatory assets are taken from each utility's recent annual report. Moody's cost-analysis model is not publicly available, but Moody's documentation provides information sufficient to replicate its model.

\section{Level of Aggregation}

The utility is the unit of observation. The break-even prices for capacity and the market prices for capacity and energy are the result of supply and demand conditions within each NERC region. Utility generation, purchased-power contracts, and regulatory assets are assessed separately.

\section{Categories Included}

The categories included are the same as for the level of aggregation. 


\section{Costs Included}

Utility-owned generation includes all fixed production costs, such as depreciation expense, taxes, nonfuel O\&M, and interest payments on debt (but not ROI). For power purchases, all fixed payments are included. All regulatory assets from each utility's annual report are included.

\section{Market Price (Value) Determination}

Moody's approach estimates market prices for capacity and energy for each of NERC's nine regions. The market price for capacity is used directly to estimate transition costs. The market price for energy is used to estimate the break-even price for capacity.

The market price for capacity is based on the marginal cost of the most expensive unit needed to satisfy forecasted demand in each NERC region. Moody defines marginal cost as the difference between nonfuel O\&M expenses and any margin a plant earns from selling energy above its variable costs. Using historical data from FERC Form 1 for the most recent three-year period, Moody estimates the marginal cost for every generating plant in a NERC region. These plantspecific cost estimates are then used to construct a capacity supply curve with marginal cost $(\$ / \mathrm{kW})$ on the $y$-axis and regional capacity $(\mathrm{kW})$ on the $\mathrm{x}$-axis. Individual plants are plotted in order of increasing cost. For each year from 1995 through 2004, Moody uses NERC projections on regional annual peak demand to estimate an annual market price for capacity. When the regional reserve margin is above $15 \%$, Moody uses the regional capacity supply curves to identify the plant that would need to be available to provide a $15 \%$ reserve margin for the region during that year's expected peak demand. The marginal cost for this plant defines the regional market price for capacity for that year. If the reserve margin for a region falls below $15 \%$, Moody assumes the market price for capacity will equal the cost of a new plant. The regional market prices that Moody reports are ten-year averages that range between $\$ 20$ and $\$ 45$ per $\mathrm{kW}$ per year.

Moody's uses an analogous approach to estimate the regional market price for energy. The principle underlying Moody's approach is that plants are dispatched to meet demand in order of increasing operating cost. At a specific level of demand, a given plant will not run if a cheaper alternative is available. Using historical data from FERC Form 1 for the most recent year, Moody's estimates the average variable production cost (i.e., the fuel cost, which will be a function of each plant's heat rate and the price of fuel) for each generating plant in a NERC region. These plant-specific cost estimates are then used to construct an energy supply curve with the average variable production cost $(\$ / M W h)$ on the $y$-axis and the regional average demand (MW) on the $\mathrm{x}$-axis. Individual plants are plotted in order of increasing cost. The supply curve proxies the loading order for plants in a NERC region. QF plants that do not have dispatchability provisions are treated as having variable costs of zero because the purchasing utility cannot reduce costs by avoiding production from these units. As a result, QF plants are used first in the order of dispatch. Moody's estimates the demand for a region as the average of the total production of all plants in a region over the most recent three-year period and then divides this annual production estimate by the number of hours in a year. Thus, the market price 
for energy in a region is the average variable production cost of the most expensive plant that is producing energy at the average level of demand. The regional market prices that Moody's reports range from $\$ 13$ to $\$ 24$ per $M W h$.

\section{Retail Price (Value) Determination}

Moody's does not make an assumption about the retail price or value of generating capacity or energy. Instead, Moody's estimates a break-even price for capacity. Moody's defines the breakeven price as the price a supplier must charge for each unit of capacity to recover all fixed costs after applying any margins from sales in the energy market. The relationship between the breakeven price, fixed costs, and energy margins is perhaps best illustrated for a single utility as follows:

$$
\begin{aligned}
& \text { Break-even Price }=\text { Unrecovered Fixed Costs } \div \text { Total Capacity, and } \\
& \text { Unrecovered Fixed Costs }=\text { Total Fixed Costs }- \text { Total Energy Margins. }
\end{aligned}
$$

The total energy margins are the sum of the plant-specific energy margins from plants $p=1$ to $n$ :

$$
\text { Total Energy Margins }=\sum_{\mathrm{p}=\mathrm{n}}^{\mathrm{p}=1}\left[\left(\text { Market Price for Energy } \mathrm{p}_{\mathrm{p}}-\text { Variable Production } \text { Cost }_{\mathrm{p}}\right)\right.
$$

The concept of a break-even price for capacity is motivated by Moody's belief that suppliers able to cover a greater share of their fixed costs through energy sales will be at a competitive advantage. Alternatively, suppliers that must recover a greater share of their fixed costs through capacity charges will be at a disadvantage. A company with a break-even price that exceeds the region's market price for capacity faces potential transition costs.

Where relevant, Moody's also estimates a break-even price for purchased power. Moody's expresses the energy payment contained in most $\mathrm{QF}$ contracts as a dollar per $\mathrm{kWh}$ energy charge. As in the above example, the purchase of energy at a price below the region's market price for energy yields energy margins for the utility. These total margins from all a utility's contracts are then subtracted from the fixed costs of the contracts. Any remaining unrecovered fixed costs are divided by the total amount of capacity available from the contracts. The result is the break-even price for purchased power.

Moody's includes regulatory assets in the break-even price. The total regulatory assets reported in each company's annual report are assumed to be recovered over ten years. Thus, Moody's divides one-tenth of each company's regulatory assets by the company's total $\mathrm{kW}$ capacity. The utility's total break-even price for capacity is the sum of the purchased power and utility-owned generation break-even prices, weighted by the amount of capacity, and the break-even price for regulatory assets . 


\section{Time Period}

Moody's assumes widespread competition between electricity suppliers by 2000 and uses a tenyear period, 1995-2004, to estimate transition costs.

\section{PACIFIC GAS \& ELECTRIC COMPANY(1994a, b)}

\section{Type of Method}

PG\&E's method is an administrative valuation, ex ante, top-down approach. PG\&E also includes a forecast of regulatory assets based on an annualized change in recent year-end account balances.

\section{Implementation}

Transition costs are estimated by spreadsheet, but portions of the underlying data are produced using complex computer models. The PG\&E method also calls for an annual proceeding to review transition cost estimates and supporting data. This annual proceeding includes a reconciliation process for the previous year's transition cost forecast.

\section{Publicly Available Data/Models}

Primary data on production cost simulation, base revenue, QF deliveries and contract terms, and regulatory assets are found in testimony or can be found in rate case filings, standard offer contracts, and utility balance sheets.

\section{Level of Aggregation}

Utility generation, QF contracts, and regulatory assets are assessed separately. The PG\&E approach demonstrates the use of a top-down valuation approach that links transition costs to different asset categories.

\section{Categories Included}

The categories are the same as for the level of aggregation.

\section{Costs Included}

The total revenue requirement associated with utility electricity production and QF contracts as well as regulatory assets that the utility believes are at least partially related to electric generation (deferred taxes, fuel adjustment clause, unamortized loss on reacquired debt, workers' compensation, energy sales discounts to the Western Area Power Administration, QF buyouts, and other regulatory assets) are included. The revenue requirement for utility generation includes 
fixed costs, variables costs, and return on base revenue. The revenue requirement for $\mathrm{QF}$ contracts includes all costs specified in contracts, such as energy payments, capacity payments, and other fixed-cost payments.

\section{Market Price (Value) Determination}

Market price is determined exogenously by assumption. The assumption is based on observations of recent bids for new, long-term, firm baseload generation at the busbar (3.5\&$4 \phi / \mathrm{kWh})$. PG\&E examines three market-price cases $(3.2 \phi, 4.0 \phi$, and $4.8 \phi / \mathrm{kWh})$.

For comparison to utility-owned generation, the utility assumes a market price for the first year of the forecast. The market price is composed of variable (2/3) and fixed costs $(1 / 3)$ in this first year. The fixed cost component is adjusted by a system load factor assumption. While not stated, we presume the rationale for this adjustment is that the $4 \notin / \mathrm{kWh}$ is for baseload power operating at a very high load factor. As a result, the utility adjusted the fixed cost component for a load - factor that more closely corresponds to the utility system load factor (the lower load factor increases the market price estimate). For the rest of the forecast interval, variable and fixed costs are projected separately. Variable costs are escalated by forecasted changes in natural gas prices while fixed costs are escalated by forecasted changes in the Consumer Price Index. For each year of the forecast, the sum of variable and fixed costs equals the assumed market price.

For comparison to $\mathrm{QF}$ contracts, the utility uses the same approach but does not make a load factor adjustment. Thus, the market prices used to estimate transition costs for utility-owned generation and $\mathrm{QF}$ contracts differ substantially (the former is more than $10 \%$ below the latter).

It is not clear why the utility treats these categories differently.

\section{Retail Price (Value) Determination}

For utility-owned generation, the retail price is the total annual revenue requirement divided by the total annual generation. The total revenue requirement for utility-owned generation is the sum of base revenue for production (total production base revenue minus plant decommissioning expense), nuclear costs (forecasted generation times utility-proposed settlement price), and nonnuclear fuel costs. The utility proposes that authorized generation revenue for future transition costs estimates be set using a performance-based rate-making mechanism. PG\&E argues that such a mechanism will constrain generation prices and provide incentives for the utility to reduce costs. The utility treats decommissioning expenses as an ongoing public policy obligation, similar to energy efficiency and environmental programs, that will continue beyond the transition to a new industry structure. The utility recommends that these costs be recovered using a separate charge that is applicable to all electricity users. Base revenue contains an ROI. The cost components of utility retail price are consistent with the market price, except that the former includes an explicit return on the production rate base.

For QF contracts, the retail price is the total annual payments (which may include energy payments, capacity payments, and other fixed-cost payments) divided by the total energy 
deliveries. The utility assumes that all contracted generation from QFs must be accepted and simply passes through these costs.

\section{Time Period}

For utility-owned generation the time period is 20 years, which is the approximate remaining life of generation assets and obligations. For QF contracts the time period is the duration of existing contracts, some of which run through 2026. Regulatory assets are taken at year end and amortized over 20 years.

\section{RESOURCE DATA INTERNATIONAL, INC. (1994a, 1994b) ${ }^{13}$}

\section{Type of Method}

The RDI method is an ex ante, bottom-up administrative valuation. RDI's approach includes a production cost analysis for individual utilities and market areas using a linear programming model that seeks to minimize use of the most expensive resources subject to transmission system constraints, such as wheeling charges. The basis of the transition cost estimate is a comparison of costs and revenues associated with individual generating plants. These plant-specific differences are aggregated by company to develop individual utility estimates.

\section{Implementation}

Computer models are the primary implementation tools.

\section{Publicly Available Data/Models}

Models are proprietary but are available for use under a license agreement. The data used to drive models are publicly available. Actual unit heat rate data are proprietary, but the method makes estimates using data from publicly-available sources.

\section{Level of Aggregation}

Individual assets, including utility-owned generation and regulatory assets, and individual liabilities, including QF contracts, other power-purchase contracts, and fuel contracts are the units of analysis.

The production cost portion (IREMM) includes both utility- and nonutility-owned generation.

\footnotetext{
${ }^{13}$ Important sources also included W. Coste, IREMM, Inc., personal communications (June 5, 14, and 23, 1995); T. Feiler, RDI, Inc., personal communications (June 8 and August 3, 1995); and Feiler and Seiple (1995).
} 


\section{Categories Included}

Utility-owned generation, regulatory assets, long-term coal supply contracts, long-term powerpurchase contracts (between utilities, between utilities and QFs, between utilities and independent power producers) are included in the analysis.

\section{Costs Included}

For utility-owned generation, all production costs, including depreciated capital (fixed) costs are included. The fixed cost portion includes shareholder's ROI. For power-purchase contracts, current modeling does not include individual contract terms for nonutility generators. Instead, IREMM estimates each nonutility generator's operating costs and then compares these costs to prices available from wholesale markets to determine unit dispatch. IREMM is capable of handling nonutility generators in more detail. For fuel-purchase contracts, all costs specified in the contracts are included. All regulatory assets from FERC Form 1 are included.

\section{Market Price (Value) Determination}

IREMM produces a multi-year price forecast based on market simulation of buyers and sellers in a competitive environment. The model develops a forecast of energy transactions for 61 market areas. The model uses unit-level cost data and includes technology-specific O\&M costs, regional fuel prices, transmission and wheeling costs and constraints, environmental compliance costs, and operational and scheduling constraints. The price forecast builds from production cost simulations of individual utilities (including unit dispatching and maintenance scheduling). For the first model iteration, individual utilities dispatch units to meet their internal load. For each utility or market area, the model then calculates both the energy surplus at different price levels and the utility's willingness to purchase at different price levels. The interaction of each utility's surplus and purchase functions, in addition to the cost of transmitting energy between companies, determines market prices. The market prices are, in effect, determined by an auction of the surplus energy to the highest bidder (net of wheeling expense), and the resulting prices define a spatial equilibrium where supply and demand are satisfied simultaneously. For the RDI study, wheeling charges are assumed to be $\$ 5 / \mathrm{MWh}$ for each party through which energy is wheeled.

The model permits transactions within and between interconnected systems. Interconnected regions are NERC subregions or regions. The model allows wholesale market transactions between subregions and regions where transmission exists. Interconnections between the Eastern Interconnected Systems, the Western Interconnected Systems and the Electric Reliability Council of Texas are assumed not to be used. For the East Central Area Reliability Coordination Agreement, market transactions are allowed between individual utilities. Texas is also disaggregated to permit market transactions between individual utilities. Weak physical interconnections between NERC regions may be modeled with economic variables (high wheeling charges). 
IREMM forecasts each utility's generation (to meet either native loads or to make sales in the wholesale market) and tracks the utility's annual operating revenues from its generating units (where operating revenues equal generation times market price).

For power-purchase contracts, RDI uses a weighted average of IREMM monthly price output by time period to estimate a weighted annual average market price. This market price is then compared to the price specified in each contract.

For coal-supply contracts, RDI estimates spot prices for coal. The spot price estimates are made for each coal-fired electric utility generating plant that purchases coal on the spot market. For plants that do not purchase spot coal, RDI uses an average of spot prices from purchases made by neighboring plants.

\section{Retail Price (Value) Determination}

For utility-owned generation, RDI compares the variable and embedded fixed costs for utility generation to the market price for each of 8829 generating units. For each utility company, RDI adds the difference between the revenues obtained (generation times market price) and cost (variable plus fixed costs) for each generating plant. RDI defines transition costs as the portion of fixed costs not recovered from utility operating revenue. The simulation model assumes a capacity-value of $\$ 55 / \mathrm{kW}$-year, which acts as a "reservation charge" that would be paid by end users in a competitive market to ensure that if purchased energy is subsequently auctioned to a higher bidder, energy can still be obtained at peak-period prices.

For power-purchase contracts, retail price is the total cost by contract, including energy and capacity payments (and other fixed payments). Energy deliveries are those specified by the contracts. RDI compares the total cost to market price for each contract. At the utility company level, RDI adds the difference between revenue and cost for each contract; transition costs are the present value of stream of future costs in excess of future revenue.

For coal-purchase contracts, retail price is the total cost by contract. Fuel deliveries are those specified by contract. RDI compares the total cost to market price for each contract. At the utility company level, RDI adds the difference between revenue and cost for each contract; transition costs are the net present value of stream of future costs in excess of future revenue.

For regulatory assets, RDI reports the balances currently carried on utility books and reported to FERC.

\section{Time Period}

The time period is ten years for utility-owned generation. RDI's QF and fuel supply analyses run from 1994-2000; RDI assumes that although some contracts run much longer, competitive pressure will be great to renegotiate these contracts. 
SANT AND NAILL (1994)

\section{Type of Method}

Sant and Naill propose an ex ante market valuation, which can be implemented as a bottom-up or top-down approach, or both.

\section{Implementation}

Implementation is through a sale of individual generating assets or packages of assets either through a public offering or a spin-off. The utility conducts this auction. An important condition for the sale is that utilities are guaranteed at least book value for assets. In return, prospective buyers are offered a fixed-price contract from the utility for power generated over the rest of the asset's economic life (i.e., until full depreciation). Utility-affiliated generating companies may participate in the sale if the parent company has spun off the affiliate so that there is no longer any association with the parent utility. The fixed-price contract includes the remaining undepreciated capital costs for the asset, including an ROI, fuel costs, and nonfuel O\&M costs. This contract contains the stranded asset cost from the generation facility. Based on these costs, the utility calculates a rate schedule that includes a $5 \%$ reduction in the overall rate needed to recover the above costs. After the contract expires, the owner negotiates new contracts at competitive market rates or sells on the wholesale market. The length of the contracts defines a transition period that precludes retail wheeling or direct retail access.

Sale of nuclear assets requires additional features. Buyers may require federal insurance protection to guarantee disposal of nuclear waste and decommissioning costs. It may also be necessary to require the utility itself to bid on its own nuclear plants. In the event that no other party bids, the plants remain in their current status.

Finally, plants with long-run operating costs that exceed the long-run marginal costs of generation should be shut down. Regulators should ensure that utilities are allowed to fully recover the undepreciated book value of these assets.

\section{Publicly Available Data/Models}

Data are not publicly available, but potential buyers know the cost structure of the assets for sale, at least as estimated by the utility.

\section{Level of Aggregation}

Several options are available. Assets may be sold individually or in packages. These packages may combine competitive and less competitive plants (or portions of less competitive plants). For example, a desirable hydro unit might be sold with a portion of a nuclear plant. Presumably, the utility is guaranteed recovery of the total combined book values of the packaged assets. 


\section{Categories Included}

Utility-owned generation is the unit of analysis.

\section{Costs Included}

The costs included are fixed costs, variable costs, and an ROI for generation. These total costs are then discounted by at least $5 \%$.

\section{Market Price (Value) Determination}

The market value is determined by the winning bid price, but must at least equal the book value of the asset(s).

\section{Retail Price (Value) Determination}

The retail value is determined by the utility in the rates or terms of the long-term power purchase contract provided to the buyer as a condition of the asset sale. After the contract expires, the market and retail values should, in principle, be identical because the asset owners must renegotiate contracts at competitive market rates or sell power on the wholesale market.

\section{Time Period}

The initial power-purchase contracts are tied to the economic lives of the purchased assets (or perhaps an average life for asset packages). This time period will differ by utility. In addition, the nationwide sale of assets should stretch over a long period, perhaps ten years or more. The proposal envisions asset sales proceeding on a state-by-state basis. Thus, all generating assets in one state might by sold in the next year or two, but generating assets in another might not be sold for several years. 


\section{INTERNAL DISTRIBUTION}

1. D. Bauer

2. L. Baxter

3. V. D. Baxter

4. L. Berry

5. D. S. Bjornstad

6. R. Braid

7. M. A. Brown

8. J. Christian

9. G. Courville

10. T. R. Curlee

11. P. D. Fairchild

12. S. Hadley

13. L. J. Hill

14. E. Hillsman

15. E. Hirst

16. P. J. Hughes

17. B. Kirby

18. R. Lee

19. P. Leiby
20. J. M. MacDonald

21. V. C. Mei

22. D. E. Reichle

23. D. T. Rizy

24. A. C. Schaffhauser

25. M. Schweitzer

26. R. B. Shelton

27. J. Tomlinson

28. B. E. Tonn

29. J. Van Dyke

30. J. Vancoevering

31. J. M. Veigel (ORAU)

32. T. J. Wilbanks

33. ORNL Patent Office

34. Central Research office

35. Document Reference Section

36. Laboratory Records (RC)

37-39. Laboratory Records Dept.

\section{EXTERNAL DISTRIBUTION}

40. Dr. Thomas E. Drabek, Professor, Department of Sociology, University of Denver, Denver, CO 80208-0209

41. Dr. Stephen G. Hildebrand, Director, Environmental Sciences Division, Oak Ridge National Laboratory, Post Office Box 2008, Oak Ridge, TN 37831-6037

42. Mr. George F. Sowers, P. E., Senior Vice President, Law Companies Group, Inc., 114 Townpark Drive, Suite 250, Kennesaw, GA 30144-5599

43. Dr. C. Michael Walton, Ernest H. Cockrell Centennial Chair in Engineering and Chairman, Department of Civil Engineering, University of Texas at Austin, Austin, TX 78712-1076

44.-46. OSTI, U. S. Department of Energy, P. O. Box 62, Oak Ridge, TN 37831

47. Office of Assistant Manager for Energy Research and Development, DOE/ORO, P. O. Box 2001, Oak Ridge, TN 37831-8600

48.-800. External Energy and Global Change Analysis Section distribution mailing list and extra copies to E.M. Schorn, 4500N, H-19A 
